\title{
Journal of Planning Literature
}

http://jpl.sagepub.com/

\section{Quality of Life in the Planning Literature \\ J. -C. Dissart and Steven C. Deller \\ Journal of Planning Literature 2000 15: 135 \\ DOI: $10.1177 / 08854120022092962$}

The online version of this article can be found at:

http://jpl.sagepub.com/content/15/1/135

\author{
Published by: \\ (\$) SAGE \\ http://www.sagepublications.com
}

Additional services and information for Journal of Planning Literature can be found at:

Email Alerts: http://jpl.sagepub.com/cgi/alerts

Subscriptions: http://jpl.sagepub.com/subscriptions

Reprints: http://www.sagepub.com/journalsReprints.nav

Permissions: http://www.sagepub.com/journalsPermissions.nav

Citations: http://jpl.sagepub.com/content/15/1/135.refs.html 
CPL Bibliography

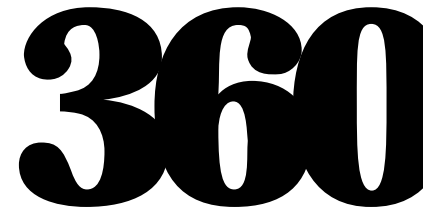

\title{
Quality of Life in the Planning Literature
}

\author{
J.-C. Dissart \\ Steven C. Deller
}

This bibliography reviews the literature on the notion of quality of life and how it affects several planning issues. The concept of quality of life is examined in general terms through definitions, concepts, models, and methods. Following this are discussions on quality of life as it relates to places or geographic areas, primarily urban ones, but also rural areas and neighborhoods; the role of quality of life in human migration; the impact of quality of life on firm location; and the relationship between quality of life and regional economic growth. The authors conclude that quality of life will increasingly play a significant role in various planning dimensions, but that role is likely to be a complex one.

TABLE OF CONTENTS

I. Introduction
A. Quality of Life in General
B. Quality of Life and Places
C. Quality of Life and Migration
D. Quality of Life and Firm Location
E. Quality of Life and Growth/Development

\section{F. Conclusion}

G. References

II. Annotated Reference List

A. Quality of Life in General

B. Quality of Life and Places

C. Quality of Life and Migration

D. Quality of Life and Firm Location

E. Quality of Life and Growth/Development

III. Index by Author

\section{INTRODUCTION}

Quality of life can mean different things to different people, encompassing such notions as "well-being" centered on the individual to "good place" centered on

J.-C. DISSART is a graduate student in urban and regional planning at the University of Wisconsin-Madison.

STEVEN C. DELLER is a professor of agricultural and applied economics at the University of Wisconsin-Madison.

Journal of Planning Literature, Vol. 15, No. 1 (August 2000). Copyright (c) 2000 by Sage Publications, Inc. 
the location. Whichever approach is considered, the notion of quality of life has considerable implications for planning. For example, a city reputed for its quality of life might find it easier to promote its economic development by attracting certain industries or specifically skilled workers. Also, indicators of quality of life can help planners monitor their community and draft new plans or review existing ones accordingly. This article reviews the notion of quality of life and how it affects human migration, business location, and growth/development in general.

The review of literature started with an initial set of articles dealing with the issue. A second set of references was derived by studying the bibliographies of the first set of articles. Then, a search of the database ProQuest ${ }^{\circledR}$ was conducted for the period 1985-99 using the following key words: amenities and growth, amenities and migration, and amenities and quality of life. As a complement, an analysis of the articles featured in the periodical Social Indicators Research (an international and interdisciplinary journal for quality-of-life measurement) was conducted for the period 1989-99. Finally, the Books and Articles section of the Journal of Planning Literature was analyzed for the period 1989-99 for the following categories: urban sociology, rural sociology, community and neighborhood development, small town/rural development, regional planning and development, economic development and growth, environmental planning, environmental quality, sustainability, recreation/open space planning, environmental perception, lifestyle, and sociospatial factors. This review of literature looks primarily at the U.S. situation, complemented-to a much smaller extent-by Canadian, European, and Australian experiences.

The remainder of the article is divided into five sections. In the first section, we examine the concept of quality of life in general terms, through definitions, concepts, models, and methods. Quality of life as it relates to places or geographic areas, primarily urban ones, but also rural areas and neighborhoods, is reviewed next. The third section addresses the role of quality of life in human migration. In the fourth section, we describe the impact of the quality of life on firm location. Complementing the two previous sections, we then examine the relationship between quality of life and regional economic growth/development. We end by summarizing the main findings of the study.

\section{A. Quality of Life in General}

The term quality of life does not have a clear origin (Szalai 1980). Although it has common sense appeal and meaning, quality of life does not have a generally accepted definition either. Roughly speaking, however, quality of life refers "to the more or less 'good' or 'satis- factory' character of people's life" (Szalai 1980, 8). The concept has several interesting attributes (Szalai 1980): (1) it refers to human life only, (2) it is rarely if ever used in the plural, (3) it is used as a single indivisible generic term whose meaning can be clarified, and (4) it is difficult to classify into any discrete category of related social sciences.

Romney, Brown, and Fry (1994) attempted to explain why there is no universally accepted definition of quality of life: (1) psychological processes relevant to experiences of quality of life can be described and interpreted through many different conceptual filters and languages; (2) the concept of quality of life is to a considerable degree value laden; and (3) the concept of quality of life embodies the understanding of human growth and developmental processes, the average life span of individuals within their communities, and the extent to which these psychological processes are influenced by environmental factors and individual value systems.

The lack of a standard definition has led to the interchangeable use of the term quality of life with other concepts, such as well-being, level of living, way of life, life satisfaction, happiness, and morale, to name a few. Some scholars put quality of life on a continuum; others argue that quality of life is a multidimensional concept. In spite of the diversity of concepts to measure quality of life, a number of authors have observed that there are high intercorrelations between them. This may be why there has been little effort to impose either empirical or theoretical order on the various constructs (Evans 1994).

Whatever the term used, a person's quality of life is dependent on the exogenous (objective) facts of his or her life and the endogenous (subjective) perception he or she has of these factors and of himself or herself. This is the first dichotomous category recognized by most scholars.

Thus, research on quality of life attempts to measure the combined effect of these objective and subjective factors on human well-being. "Objective measures, or social indicators, represent in a broad sense the individual's standard of living represented by verifiable conditions inherent in the given cultural unit" (Evans 1994, 53). Subjective quality of life has been defined as "the degree to which the individual's life is perceived to match some implicit or explicit internal standard or referent" (Evans 1994, 53). Szalai (1980) merged the two approaches and accepted social indicators as based on subjective measures as well. To Szalai, indicators of quality of life are social indicators insofar as they characterize the well-being of certain groups of people, but, contrary to other social indicators, they are based both on objectively observable facts and on people's own subjective assessment of their life. 
The debate about the distinction between, and the relative importance of, these two sets of factors is vivid (Szalai 1980). But there is a recognition that a greater integration of the two types of indicators would be fruitful, especially since these terms can be inappropriate and misleading, as they are subject to measurement errors, imprecision, and instability assessments (Andrews 1980).

This leads us to discuss quality-of-life measurement issues. They include the use of global-versus domainspecific measures (overall quality of life, e.g., "How satisfied are you with your life?" as opposed to quality of life in distinct domains, e.g., "How satisfied are you with local government services/your children's school?") and the stability of types of measures and/or domain measures over time. The list of factors related to quality of life is virtually limitless. Examples of models and empirical studies given below will make up such a list. But a review of the literature suggests a number of general, important, and potentially interactive dimensions to take into account when measuring quality of life: personality, social support, personal satisfaction in several domains (e.g., employment or marital life), personal skills, environmental factors, economic factors, health, and stressful events.

Studies of quality of life can be cross sectional or longitudinal, with single or multiple variables. Two popular models have been proposed to explain the relationship between quality of life and other variables: the top-down model "based on the premise that quality-of-life is an enduring characteristic that causes certain outcomes in the individual's life" (Evans 1994, 61) and the bottom-up model, which "rests on the proposition that particular variables influence an individual's quality-of-life" (Evans 1994, 61).

Diener and Suh (1997) argued that there are three major philosophical approaches to determining quality of life: (1) characteristics of quality of life dictated by normative ideals based on religious, philosophical, or other systems; (2) the satisfaction of preferences (choice utility); and (3) the experience of individuals. These approaches are related to three measures of quality of life: social indicators, economic indexes, and wellbeing. Diener and Suh argued that an integration of the three measures would facilitate informed policy making.

Wheeler (1991) used the General Well-Being Questionnaire to measure the quality of life of people about to enter a health promotion program. The General Well-Being Questionnaire consists of 143 statements for which responses indicate degree of agreement on a 5-point Likert-type scale. Statements contribute to a total of thirty variables that are further grouped via factor analysis into seven factors: emotions, beliefs, activity, general environment, easy goingness, tempera- ment, and health. The results support the fact that general well-being consists of a complex set of psychologically measurable variables, the most important of those being emotional variables (e.g., happiness, coherence, sense of purpose, and social relations).

Shye (1989) developed a framework to construct a two-facet definition of quality of life: one field of functioning facet including four subsystems (personality, physical, social, cultural) and one subsystemic mode facet including four modes (expressive, adaptive, integrative, conservative). Because each of the four subsystems includes the four modes defined above, the two facets result in sixteen content areas that can be covered by an observable variable yielding information on the effectiveness of an individual's functioning in the various modes.

Andrews (1991) studied the level and structure of subjective well-being in the United States in 1972 and 1988. Both studies were based on a questionnaire with two sets of quality-of-life measures: two measures of global well-being and twenty-four assessments of specific life concerns. They included assessments of oneself, fun, health, income and standard of living, several aspects of one's job, marriage and children, spare time and social activities, community/neighborhood, and local and national government. Using factor and multiple classification analyses, results showed that although changes were found in the levels of some of the measures, the structure of well-being remained constant over the sixteen-year period.

Headey (1993) suggested inserting psychologists' variables into an economist's framework to account for households' well-being. In his model, well-being is a function of stocks (family support, friendship network, leisure skills and equipment, work skills and equipment, health, wealth), background (gender, age, personality, general knowledge, social status), and flows (psychic income: family, friendship, leisure, work, health, finances). Stocks include some of the variables that psychologists identify as important to well-being; flows are daily activities and the satisfaction/dissatisfaction obtained from them.

Finally, using a geographical perspective, Cutter (1985) proposed a model of quality of life incorporating objective and subjective information along three dimensions related to place: social, environmental, and perceptual. In evaluating places, Cutter argued that one should consider not only objective indicators and subjective assessments of the social environment (crime, housing, income) and physical environment (climate, pollution, recreation) but also their relative importance with a more subjective assessment of people's image of a place.

This first section introduced the concept of quality of life and emphasized the existing lack of agreement on 
definitions, approaches, and measures related to it. Most empirical approaches involve conceptualizing a model and testing it using quantitative data, usually obtained via Likert-type scale answers. Comparing the results of a scale values approach with those of an intensive qualitative study conducted on quality of life among elderly people, however, Wood and Johnson (1989) found a number of unsystematic discrepancies across participants and domains. As a consequence, they recommend employing quantitative approaches as supplements only to qualitative data and analysis.

\section{B. Quality of Life and Places}

The previous section dealt with the concept of quality of life in general and how it was modeled and measured, focusing on human beings. Although, as previously stated, quality of life as a concept refers to human life only, this section addresses the question of quality of life as it relates to places, specifically a geographical dimension of quality of life. Examining methods used to evaluate quality of life in various places is an easier way to review the literature on the subject.

Thus, one approach is to collect data from the residents of a particular place and evaluate their quality of life through their responses to a survey that is structured around Likert-type scale responses. Then, quality-of-life measures are regressed on a number of independent variables related to the place of interest or that serve as control variables. Analysis of regression results yields information as to which factors are more important in predicting well-being.

For example, Crider, Willits, and Kanagy (1991) studied the well-being of rural people as it related to their community. They studied a panel of persons from rural areas in Pennsylvania. One question of well-being asked: 'How satisfied are you with your way of life in this community?' The response was scored on an ordinal scale. Questions also asked about friends in the community, relatives in the area, religious beliefs, and place of residence. Results showed the association of place of residence to happiness, even when income was controlled, although place of residence did not explain a large proportion of the variation in scores that did occur. For country residents, income was second to friends in predicting well-being, and the other way around for urban dwellers.

Jeffres and Dobos (1995) explored the relationship between perceived quality of life and related domains. They completed three surveys in 1982,1986, and 1988 of the residents of a major midwestern city in the United States. The study distinguished two sequences of quality of life: metro area (in relevant domains: housing, schools, justice-police, government services, transportation, culture-leisure, employment, outdoor recreation, neighborhood) and one's satisfaction with life (in personal domains: family, work, leisure, significant groups). Control variables included achievement-oriented factors (income, education, occupational status), ascriptive factors (gender, ethnicity), and life cycle factors (marital status, age). Results confirmed bivariate relationships between factors and between global quality-of-life measures and domain assessments.

Although the overall, general approach remains the same, articles included in the annotated bibliography indicate several variations to this first approach of estimating quality of life as it relates to places (Nos. 27, 35, $40,41,52)$. A panel may or may not be used, quality of life may be an overall measure or approximated via a number of dimensions, and the setting might be the suburbs or a community in general, addressing sense of community or technological hazards.

The other approach is to use a mix of primary and secondary data. For example, Rogerson et al. (1989), using Cutter's (1985) model of quality of life, combined both objective (secondary) and subjective (primary) indicators to estimate the quality of life in British cities. Perceptual evaluation and weightings of indicators were derived from a stratified national opinion survey on the relative importance attached to various dimensions (social, economic, environmental) of quality of life with respect to choice of residential location. Then, objective indicators were selected to represent each of the rated dimensions of quality of life. Fifty indicators were standardized and averaged to illustrate quality-of-life dimensions. The rank of individual cities was calculated by multiplying the score on each dimension by the appropriate weighting.

Another approach is to build scales, but using secondary data only. Liu (1976) did the founding work in this approach. (Liu also collected primary data, but only on sports and cultural events from chambers of commerce, and assigned them a weight of .039 on the social component!) Liu provided a theoretical framework and a set of comprehensive quality-of-life indicators for 243 Standard Metropolitan Statistical Areas (SMSAs) in the United States in 1970. One-hundred and twenty-three factors and variables were measured through five different quality-of-life components to build an objective measure of quality of life: (1) economic (individual economic well-being and community economic health), (2) political (individual political activities, local government professionalism and performance, and welfare assistance), (3) environmental (types of pollution such as air, water, noise, visual, and solid waste and types of natural environment such as climatological data and parks, trails, and recreational areas), (4) health and education (individual health, educational attainment, community educational investment and medical care provision), and (5) social (individual equality, individual concerns, level of community living conditions). 
Liu (1976) used an adjusted standardized additive method with an equal weighting scheme to generate quality-of-life indexes for each of the five components. The 243 SMSAs were divided into three groups (large, medium, and small), and the quality of life of the SMSAs were then identified to be either substandard, adequate, good, excellent, or outstanding. According to Liu, the weakest point of the study was its failure to take into account the psychological aspects of the individual's perceived quality of life.

Since then, as documented in the annotated bibliography, this method has been used extensively to evaluate stress or quality of life in cities as well as in states. In particular, numerous guides have been edited, compiling statistics and rating places in more or less explicit ways to sort out the best places in the United States, from small to big cities, for business, or for living (Nos. $37,46,57,58,59,62$ ).

The last approach consists of determining implicit prices for specific amenities that are supposed to reflect the quality of life in a particular place. Virtually all of these studies are based on aggregate cross-sectional data and employ regression methods, in which wage rates are related to attributes of cities and to other factors that influence wages, such as education and age. Rosen (1979) and Roback (1982) did the founding work in this approach.

Rosen (1979) computed a quality-of-life index among metropolitan areas from wage data. Rosen explained that such an index might be inferred from the nonmarketable attributes (amenities) offered by different places that people must pay for to live and work in those places. Using 1970 data from the Current Population Survey, implicit amenity prices were estimated by regressing real wages on indicators of amenities (believed to be relevant for location choice) after controlling for personal productivity differences (such as education and race) that also affect wage rates. Five major groups of place attributes were distinguished: pollution, climate, crime, crowding, and market conditions. Thus, the attribute regression coefficients had the dimensionality of prices (\$/unit of each attribute), which served as the value weights in the construction of an index of urban amenities on a per household basis. Places were subsequently ranked according to their level of quality of life.

Roback (1982) extended Rosen's (1979) work by including the housing market in the study of the implicit price of amenities. It was assumed that the value of the amenity is reflected in both the wage and the rent gradients. At equilibrium, in all occupied locations, wages and rents adjust to equalize utility, which depends on the composite commodity consumed, the residential land consumed, and the endowed amenity. Amenity variables in the study included population density, heating degree days, total snowfall, number of cloudy days, and number of clear days. The empirical work on wages showed that the regional wage differences could be explained significantly by these local attributes. Using site price data, implicit prices were estimated and quality-of-life rankings for the cities were derived.

Many studies along the lines of Rosen (1979) and Roback (1982) have been used to derive city rankings (Nos. 28, 29, 38, 39, 42, 43, 61). They vary according to the variables included for the estimation of amenity values. They usually encompass climatic (e.g., cooling degree days), environmental (e.g., total suspended particulates), and urban (e.g., violent crime, teacherpupil ratio, housing, local government, and fiscal) conditions. But they also vary according to the functional form of the estimating equation, the issue of single versus multiple markets, and the unit of analysis (cities, SMSAs, counties). As a result, quality-of-life rankings are highly variable. The hedonic approach can be used not only to assess amenities and derive urban area rankings but also to address the issue of optimal urban size, on which, considering the results' variability, little progress has been made.

In conclusion, based on the empirical literature, it is difficult to make recommendations about how to improve the quality of life in particular places. Many studies have attempted to obtain a value for amenities from which quality of life is supposed to derive. These studies do suggest, however, that not all amenities are so location specific that local government cannot control them. For example, fiscal management, local levels of pollution, and quality of public services can certainly be acted on by local decision makers. In addition, studies about quality of life in neighborhoods suggest that promoting the social fabric of communities would improve the quality of life in those places. At the same time, consumer preferences for privacy push people to live in rural areas, or at least at the rural-urban fringe, which means sprawling urban development. Cluster housing, by preserving agricultural land while providing people with satisfying places to live, may be part of the answer to this contradictory position.

\section{Quality of Life and Migration}

The U.S. society is sometimes thought of as being constantly on the move. The United States has actually known tremendous demographic shifts in the past thirty years. According to Greenwood (1985):

In recent years trends in the spatial distribution of population in the United States have undergone dramatic changes. After many decades during which the West experienced the greatest volume of net in-migration, the South has, since about 1970, had a volume of net 
in-migration about twice that of the West. Moreover, the rate of population growth in metropolitan areas slowed considerably, in part because the central-city population of many metropolitan areas declined and the suburban growth boom of prior years moderated appreciably. Partially as a cause and partially as a consequence of these changed circumstances, the historical trends of migration out of nonmetropolitan areas and into metropolitan areas reversed such that population in nonmetropolitan America began to grow more rapidly than that in metropolitan America. (P. 522)

Thus, two distinctive patterns can be isolated: a regional shift (migration to the U.S. South and West) and an urban-to-rural shift (also known as the population turnaround). According to Greenwood (1985), between 1970 and 1980 approximately 90 percent of the nation's incremental population accrued to the South and West, a figure "sharply higher than that for any other decade in U.S. history" (p.522). This regional shift was the result of internal migration, natural increase (due to greater concentrations of populations in the childbearing years in the South and West), and international migration (which predominantly crossed southern and western borders).

On the other hand, rural population gains through net migration have risen steadily during the late 1980s and early 1990s. During the first half of the 1990s, nonmetropolitan areas grew by 1.55 million persons through net migration. The population turnaround has a number of causes and consequences that "tend to be self-reinforcing and cumulative" (Greenwood 1985, 525). These factors include (1) the physical expansion of cities resulting in residential development in rural areas; (2) the declining relative importance of distance; (3) the increased economic viability of nonmetropolitan areas due to the development of natural resources and the relocation of economic opportunities from urban centers to rural areas; (4) the possible diseconomies associated with dense urban locations; (5) the small size of the rural population, which makes rural-urban migration difficult; and (6) general quality-of-life factors (Beesley and Bowles 1991; Greenwood 1985). The latter include perceptions of the community environment, changes in lifestyle (slower pace of living), less crime, better environmental qualities, better life for children, lower cost of living, and access to recreational opportunities. However, these rapid changes represent potential disturbances to a community's social organization (Beesley and Bowles 1991).

Finally, Heubusch (1998) documented the growth of micropolitan areas, small cities located beyond metropolitan areas and suburban sprawl and comprising at least fifteen thousand residents. Some of these areas grew more than 20 percent for the years 1990-94 (U.S. average $=4.4$ percent) as a result of people's preferences for living in places offering city benefits (urban services, job opportunities, cultural amenities, landscapes) without having to endure city disadvantages (crime, high property taxes, stress, traffic). For the time being, these micropolitan areas comprise only 5 percent of the U.S. population, whereas metropolitan areas comprise 80 percent.

Whereas descriptive statistics show movements of population and attempt to provide some insights about the causes of these movements, migration theories attempt to understand what the determinants of migration are. Two determinants particularly stand out: (1) family and life cycle considerations, and (2) the application of equilibrium as opposed to disequilibrium notions in migration analysis.

In the first case, critical to an individual's (or a household's) decision to migrate are life cycle considerations (e.g., marriage, birth and aging of children, retirement) and other personal characteristics (e.g., education level, sex, health). Family ties also have an influence on the decision to migrate. For example, Currie and Halli (1989) studied factors that influence the decision to migrate to two cities located in the Canadian prairies. They found that respondents rarely expressed single motives and that family reasons were second only to economic factors as the most important reasons for migration. Educational opportunities came in third.

The second case needs more explanation. First, the disequilibrium approach refers to the issue of labor migration in the neoclassical economic perspective (Kahley 1991). The system is viewed as initially out of equilibrium, and any adjustments that occur are assumed to be equilibrating adjustments: migration is seen as part of the process whereby workers adjust to differences between regional labor markets. Labor is expected to flow from low-wage, labor-surplus areas to high-wage, labor-short regions until wage levels converge. Thus, interregional wage differentials stimulate migration from low- to high-wage regions and, thus, contribute to a narrowing of the differential. This framework is also associated with the human capital approach, which has individuals investing in migration only if it is profitable. Because moving is not costless, an individual's decision to relocate must be accompanied by the expectation of higher benefits at the new location: households migrate from areas of relatively low earnings to areas of high earnings in an attempt to increase the return on human capital.

Second, the equilibrium approach follows Tiebout's "consumer voters" (or "voting with one's foot") who are assumed to reveal their preferences for location-specific amenities and public goods as they move between places in order to maximize utility. If interregional wage differentials are in equilibrium, there is no incentive to migrate. Migration occurs only to facilitate an adjust- 
ment to a new equilibrium. "Hence, not only would changes in the relative wage structure across regions encourage migration as in the traditional models, but so too would changes in demand for nontraded goods, such as location-specific amenities, which could occur from rising real wages in all locations" (Greenwood $1985,530)$. In this framework, people are willing to accept lower wages provided compensation by a wider range of amenities. Thus, migration takes place as a result of change in demand for location-specific amenities, and does not have to result in migration from lowto high-wage areas.

Equilibrium approaches are based on the seminal works by Rosen (1979) and Roback (1982) discussed in the previous section. In the hedonic model, migration results from households' altered demand for amenities whose values are capitalized into wages and land rents: wages and the rent market adjust in order to leave utility constant over space. Characteristics that attract migrants to a place are "pull" factors; those that repel migrants are "push" factors (Kahley 1991).

The relative importance of economic versus location-specific amenities in the migration process remains controversial. However, most empirical studies that include quality-of-life factors in their models have found that these amenities are significantly important, hence showing the relevance of the hedonic approach over the human capital approach. The relative importance between the two types of factors is related to migrants' age (Heaton, Clifford, and Fuguitt 1981): economic factors are determinants of migration more for the young than for the elderly.

For example, using SMSA data, Graves (1979) showed that migrants purchase a bundle of location-specific goods. When income level and unemployment rates were taken into account, climatological amenity variables (heating degree days, cooling degree days, annual temperature variance, humidity, and wind speed) were important in explaining age- and race-specific net population migration during the 1960s. Also, the relative importance of economic opportunity and climatic amenities varies by age and by income (and, hence, by race, since nonwhites have much lower incomes than whites, on average). Later, Graves (1983) used rent alone as a proxy for the set of unpriced amenities that might affect migration to a given region. Regression results indicate that, ceteris paribus, locations offering high rents experienced net in-migration for all age groups, and that the rent coefficient was strongly significant, hence adding further support to the equilibrium approach.

Reichert and Rudzitis (1992) used multinomial logistic models to explain income changes of migrants to nonmetropolitan, high-amenity counties. Using data from a survey of fifteen high-amenity U.S. counties, they found that nearly one-half of all surveyed migrants in the labor force accepted lower incomes upon their move to these counties. Amenities and quality of life played a more important role in the migration decision than did economic factors. However, using a generalized systemic gravity model of migration and a sample of twenty-five SMSAs, Porell (1982) found that both economic and quality-of-life factors were significant determinants of migration for the years 1965-70. However, because migration is more responsive to marginal changes in economic factors than to quality-of-life factors, the long-term equilibrium thesis of migration was not supported.

In conclusion, demographic shifts did occur in the United States during the past three decades, mainly the move toward the West and the South and the population turnaround. These changes are well documented. When it comes to explaining human migration, there are two main theories: the human capital approach, in a disequilibrium framework, and the hedonic approach, in an equilibrium framework. Empirical research shows that the relative importance of economic and amenity/quality-of-life factors is a contentious issue, but in most studies regression coefficients for amenity variables are statistically significant. These results support the equilibrium approach, that is; quality-of-life factors do play an important role in explaining why people migrate.

That fact that quality-of-life factors are not always so location specific that they cannot be acted on has important consequences for planners and communities. However, because the endogeneity of many of the determinants of migration (population, earnings, rents, amenities) has been increasingly recognized, the question of the validity of these estimates has been raised. This should stimulate the use of simultaneous-equation models of migration. Finally, Michalos (1997) raised critical issues in the measurement of quality of life as related to migration, including aggregation area size, time frame selection, and population composition.

\section{Quality of Life and Firm Location}

Blair and Premus (1987) reviewed the literature on factors in industrial location. They emphasize that no two studies reveal identical findings because of regional differences, evolving conditions of production, industry-specific versus more general studies, and new firms versus expansion of existing ones. Gottlieb (1994) reviewed specifically the literature on amenity-oriented firm location and found it limited, especially when compared to the abundance of the economic development trade press. However, both Blair and Premus and Gottlieb agree that generalizations and 
policy recommendations can be made. Basically, the literature opposes two extremes in the firm location decision-making process: economic factors (profit maximization, or least cost factors) versus noneconomic factors (quality-of-life factors).

Classic location theory suggests that firms choose a location that minimizes their costs, either real or perceived. In particular, the traditional view on location decision was a transportation cost minimization problem: least cost of transporting raw materials to the plant and then processed materials to the market. Thus, firms were assumed to locate where they could maximize profits; location was a long-term investment decision.

Very often, local governments attempted to attract firms based on traditional industrial location theory (or "smokestack chasing"): tax abatement, subsidies, simplified regulations, zoning, and others. However, recent empirical evidence shows that the least cost approach to industrial location is weakly established and has not proven to be very successful. This may be because, with the shift from a manufacturing- to a service-based economy, trying to satisfy the criterion of least cost transportation may not be as relevant as it used to be and because, so far, not nearly enough attention has been devoted to service and retail firms.

The other view is that of quality-of-life issues as significant factors in locating a plant or new business. This set of criteria is not concerned with proximity but with the characteristics of a given area. In this approach, quality of life includes such concepts as proximity to residence, educational quality, and recreational and cultural opportunities. With the increasing importance of the labor skill factor and the improvement in telecommunications, recent empirical evidence suggests a shift from least cost to quality-of-life considerations in industrial location.

Limitations of this approach may be a focus on high-technology industries. These industries are particularly attractive to governments because they can be located anywhere ("footloose"), are environmentally desirable, offer high-paying jobs, utilize local skills and talents, produce high value/low weight products, and require minimal additional infrastructure investment. It may be that these firms are attracted to an area because of its quality of life. Gottlieb (1994) noted a wide agreement that "pools of technical professionals can only be maintained in an area that has a high quality-of-life and amenities that appeal to a managerial elite" (p. 272).

Nowadays, the development professional press is editing quality-of-life indexes to help business location seekers assess the quality of life in potential sites and help firms find an appropriate match for both the company and its employees (SSID 1993). Information is available at the state, metropolitan, and local (county) levels for such indicators as population, income, crime, education, health, climate, and cost of living.

Determinants of location have been estimated using two methods: surveys and econometric studies. Surveys permit one to analyze the significance of a long list of variables that might affect firm location. Survey findings emphasize the importance of markets and labor force over other aspects, particularly quality-of-life factors (Blair and Premus 1987), although the latter are more important for smaller firms because they are usually located where their owner lives (Halstead and Deller 1997). However, these findings are likely to vary according to the industrial sector considered. Survey results indicate that, first, economic factors of location-labor, markets, transportation, and access to raw materials-are the most important factors in industrial location studies. Second, the traditional economic factors of location are becoming, as a group, quantitatively less significant, since noneconomic factors have at least some influence on location. Third, technical change has increased the importance of proximity to markets as a locational factor at the expense of proximity to raw materials. Fourth, despite an important effect of state and local taxes on business location, state and local policy alone will not play a major role in the regional economic fortune.

Foster (1977) studied location decisions of industrial firms in North America across industrial categories. The economic factors considered most important by U.S. respondents were dependability/productivity of worker, wage rates, availability of skilled workers, and nearness to customers/suppliers. The quality-of-life factors considered most important by U.S. respondents were streets safe from crime day and night, good elementary and high schools, a clean environment, and good medical services. Trade-offs for an improved quality of life that were not acceptable to U.S. respondents were a smaller pool of locally available skilled workers, the increased distance to markets/suppliers, and a smaller scale of support services and firms.

Hart, Denison, and Henderson (1989) conducted a study of high-growth technology firms and traditional manufacturing establishments in Oakland County, Michigan. CEOs were sent questionnaires and asked to rate the influence of thirty-seven least cost and quality-of-life factors on location in terms of importance. As in the previous study, both economic and quality-of-life aspects were important factors for firms locating in the county. The most important factors were proximity to markets and residences, the quality of the local environment, and the area's growth potential. But significant differences existed in the locational criteria used by different industrial sectors, and the relative importance of 
criteria appeared to have shifted away from the least cost factors toward those associated with area infrastructure, especially aspects of quality of life.

On the other hand, econometric studies focus on the statistical significance of selected determinants of firm location. In general, this literature reveals that the traditional economic factors found to be important by survey respondents were also found to be important in econometric studies. Although included in measures of fiscal climate, subsidies or locational incentives have not been particularly significant predictors of firm location.

Gottlieb's (1994) policy implications derived from his review of the literature are as follows: (1) communities should focus on basics such as schools, environment, traffic, and crime; (2) amenities should be thought of in a regional context; (3) an amenities strategy should be sensitive to city size (agglomeration economies); (4) an amenities strategy is not a least cost strategy (coexistence of amenities and high cost of living); and (5) because many amenities are public goods, and because as such they incur costs, an amenities strategy is not a least tax strategy. Finally, Gottlieb recommended that quality-of-life policies be evaluated on the basis of their contribution to growth.

Blair and Premus (1987) argued that as the nation's economy continues to shift to advanced technologies, the overall importance of nontraditional locational factors will increase as traditional locational factors, although still more important in terms of overall influence, decline in significance. A potentially productive and equitable policy would be for governments to focus their efforts on improving the overall locational attractiveness of regions, placing primary emphasis on skilled labor, research, risk capital, education, recreation, cultural amenities, long-term tax policy, management-labor relations, and quality-of-life indicators. "Industrial development would largely be a byproduct of an improved overall business climate and a better community in which to live" (Blair and Premus 1987, 84).

\section{E. Quality of Life and Growth/Development}

Growth and development could be seen as resulting from the previous two sections, that is; economic growth and development occur as a result of human migration and business location. This is actually the case; many studies included in this section deal with population and employment growth simultaneously.

Kahley (1991) described the role of migration in regional growth and development models. In the neoclassical economic model, migration occurs from the low-wage, labor-surplus, high-return-to-capital region to the high-wage, labor-scarce, low-return-to-capital region. In the 1960s, a basic approach to regional eco- nomic growth assumed that increases in demand for goods a region produces and exports to other regions led to an increase in labor demand locally, inducing in-migration. Thus, increases in the demand for goods produced in specific existing regions led to increased labor demand in those regions. This is the export-based view of growth (demand-side perspective), in which people follow jobs: job opportunities pull workers from a region. An alternative approach to regional economic growth assumed that migration itself induced job growth. In particular, there is migration from the low-wage agricultural sector to the high-wage manufacturing sector. This is the supply-side perspective, in which jobs follow people: low wages push workers out of a region.

The debate about which comes first, the jobs or the people, is still central to the regional science and the economic growth and development literature. Hence, a great deal of the literature is devoted to understanding the determinants of growth and development. Several approaches have been used to examine this issue. The first approach is to review the existing literature. Kusmin (1994) selectively reviewed thirty-five empirical studies of factors associated with the growth of local and regional economies. He found that the studies differed along many dimensions, such as geographic area of interest, indicators of growth, and industry-wide versus sectoral growth. The regional characteristics hypothesized to affect regional growth also were numerous and included taxes versus public expenditures, labor market conditions, education, access to transportation, market demand, climate, and so on. Addressing limitations of the literature, Kusmin stated that substantive conclusions appeared "sensitive to differences in study design and scope" (1994, vi).

The literature suggests factors that may significantly affect regional growth and development. Wong (1998) conducted a very informative study based on an integrative research design. An initial selection of factors was made based on the existing literature. Questionnaires were sent to local economic development practitioners, who were asked to rank the selected factors. Finally, in-depth interviews were conducted with selected respondents to confirm the survey results. The resulting eleven factors were classified as either traditional economic development factors (physical factors, location, human resources, finance and capital, infrastructure, knowledge and technology, and industrial structure) or intangible factors (institutional capacity, business culture, community identity and image, and quality of life). Interestingly, "The participants consistently saw traditional factors such as land, labor, capital, infrastructure and location as the most vital ingredients to economic development. It is only after these 
basic factors are satisfied, one may turn to the softer, more intangible factors like business culture, image and quality-of-life to increase the competitive edge of a place" (p. 718).

The other approach common to the literature is to use econometric analysis to examine the most significant factors in regional growth and development. Carlino and Mills (1987) have done the seminal work in this vein. They used secondary county-level data for the 1970s to analyze the effects of economic, demographic, and climatic variables on population and employment growth in a simultaneous-equation framework. They assumed that both households and firms are geographically mobile, so that "firms enter and leave regions until profits are equalized among regions at competitive levels, and households migrate until utility levels are equalized at alternative locations. In such a model, equilibrium population and employment are simultaneously determined" (p. 40). Employment and population are affected not only by each other but also by a variety of other variables including, among others, proportion of blacks, interstate highway density, local government taxes per capita, median family income, crime rate, median school years, and regional dummies as proxies for location-specific regional amenities. Among the findings were that both people-follow-jobs and jobs-follow-people views were consistent, with employment being a little more attractive to households than population is to employment. Also, after controlling for most of the factors that vary among regions, a preference for Sunbelt states was found, showing that location-specific amenities affected population and total employment. Finally, variables that depend on public policies had little impact on either county population or total employment growth.

Following this work, other studies have examined employment and population using simultaneous equation modeling (Nos. 104, 106, 107, 114). They differ on multiple grounds: dependent variables, unit of analysis, measure and estimation of amenity attributes, initial and historic conditions, and the introduction of spatial linkages between units of analysis. From one model to another, the level of interaction between the dependent variables is highly variable. Likewise, due to model specification, the most significant amenity variables vary from model to model. However, the overall results are roughly similar and indicate a significant but complex role of amenities in regional economic growth and development.

Special mention must be made of a growing stream of literature that deals with the outdoor/wilderness recreation dimension in regional economic growth and development. There is evidence that this domain is becoming a more important aspect of U.S. citizens' lives. During 1990, nearly 8 percent of all household expenditures were in the recreation category, accounting for more than $\$ 250$ billion, and this proportion is expected to increase. Studies have identified the recreational counties and the characteristics of wilderness users (Nos. 101 and 113). Finally, Rudzitis and Johansen (1991) surveyed residents of wilderness counties and found that wilderness was an important reason why a majority of the respondents had moved to or lived in the area. They also found that both migrants and residents were opposed to opening wilderness areas for development.

As the resource economics literature demonstrates, the valuation of natural amenities is ongoing proof that people do value them and that they constitute potential earnings sources. The important question is: Is wilderness/outdoor recreation a viable alternative for rural development? Answers from research are mixed. Using econometric simultaneous-equation modeling with data from cross-sectional samples, Duffy-Deno (1997) found no negative effect of the Endangered Species Act on the nonmetropolitan county economies of U.S. West counties. Using roughly the same approach, Duffy-Deno later extended his analysis to state parks and federally owned wilderness areas, and concluded that their effect on local economies of the West was nonsignificant.

If wilderness does not have a negative effect, can it be a viable rural development strategy? Examinations of visitors' expenditures in local economies are contradictory. Using input-output multipliers based on surveys of wilderness users in four selected wilderness areas in Utah, Keith and Fawson (1995) found that visitors contributed less than 1 percent of total sales to most of these counties and did not significantly influence these economies. On the other hand, using the same tool and approach, Bergstrom et al. (1990) found that recreational spending contributed significantly to income and employment in the rural areas they studied.

\section{F. Conclusion}

Because of higher income levels, a shift to a serviceand technology-based economy, and growing environmental awareness, quality of life plays and will increasingly play a significant role in the various dimensions of places, human migration, firm location, and economic growth.

But this role is likely to be a complex one. First, there are factors that are obviously beyond the realm of public policy (e.g., climate and topography). Second, not every community in the United States enjoys and can afford the same levels of infrastructure and public service provision. Third, migrants and businesses do not all have the same requirements and expectations with 
regard to traditional and amenity factors. Fourth, both natural and human-made amenities affect the quality of life of a community.

What does this mean to planners? Planners should first determine what the objectives of an amenity strategy are: To enhance a sense of place in the community? Develop tourism? Attract high-technology industries? Attract environmentally friendly manufacturing? Attract corporate headquarters? Given the objective, planners could then develop an analysis of the strengths and weaknesses of their community with respect to the agreed-upon objectives so that better-targeted public policies can be formulated.

On the other hand, subsidy incentives are not particularly significant predictors of firm location. And, as the United States shifts to a more service-based economy, the overall importance of nontraditional locational factors will increase in significance while traditional locational factors decline in significance. This is not to say that the latter do not play a role: traditional factors (land, labor, capital, infrastructure, location) are vital ingredients for economic development. It is only after these basic factors are satisfied that one may turn to more intangible factors such as quality of life to increase the competitive edge of a place.

With that in mind, planners could devise strategies to enhance the quality of life in their communities. Depending on the circumstances, quality-of-life policies can place primary emphasis on educational quality, recreational opportunities, cultural amenities, longterm tax policy and fiscal management, crime, management-labor relations, traffic congestion, parks, design, local levels of pollution, the social fabric of the community, and so on. All of these factors play a role in making a community attractive and are amenable to change. Given their public benefit character, such policies also have the potential of being more equitable than traditional policies.

Research on the applications of a contingency theory of quality of life as adapted to community planning would be useful to practitioners. More research also needs to be done on how to integrate quality-of-life dimensions into an overall measure that is conceptually valid and empirically testable.

\section{REFERENCES}

Andrews, Franck M. 1991. Stability and change in levels and structure of subjective well-being: USA 1972 and 1988. Social Indicators Research 25: 1-30.

1980. Comparative studies of life quality: Comments on the current state of the art and some issues for future research. In The quality of life: Comparative studies, Alexander Szalai and Frank M. Andrews, eds. London: Sage.

Beesley, Kenneth B., and Roy T. Bowles. 1991. Change in the countryside: The turnaround, the community, and the quality of life. The Rural Sociologist 11, 4: 37-46.
Bergstrom, John C., H. Ken Cordell, Gregory A. Ashley, and Alan E. Watson. 1990. Economic impacts of recreational spending on rural areas: A case study. Economic Development Quarterly 4, 1: 29-39.

Blair, John P., and Robert Premus. 1987. Major factors in industrial location: A review. Economic Development Quarterly 1, 1: 72-85.

Carlino, Gerald A., and Edwin S. Mills. 1987. The determinants of county growth. Journal of Regional Science 27, 1: 39-54.

Crider, Donald M., Fern K. Willits, and Conrad L. Kanagy. 1991. Rurality and well-being during the middle years of life. Social Indicators Research 24: 253-68.

Currie, Raymond F., and Shiva S. Halli. 1989. Mixed motivations for migration in the urban prairies: A comparative approach. Social Indicators Research 21: 481-99.

Cutter, Susan L. 1985. Rating places: A geographer's view on quality of life. Washington, DC: Association of American Geographers/Library of Congress.

Diener, Ed, and Eunkook Suh. 1997. Measuring quality of life: Economic, social, and subjective indicators. Social Indicators Research 40: 189-216.

Duffy-Deno, Kevin T. 1997. Economic effect of endangered species preservation in the non-metropolitan West. Growth and Change 28 (Summer): 263-88.

Evans, David R. 1994. Enhancing quality of life in the population at large. Social Indicators Research 33: 47-88.

Foster, Robert. 1977. Economic and quality of life factors in industrial location decisions. Social Indicators Research 4: 247-65.

Gottlieb, Paul D. 1994. Amenities as an economic development tool: Is there enough evidence? Economic Development Quarterly 8, 3: 270-85.

Graves, Philip E. 1983. Migration with a composite amenity: The role of rents. Journal of Regional Science 23, 4: 541-46.

. 1979. A life-cycle empirical analysis of migration and climate, by race. Journal of Urban Economics 6: 135-47.

Greenwood, Michael J. 1985. Human migration: Theory, models, and empirical studies. Journal of Regional Science 25, 4: 521-44.

Halstead, John M., and Steven C. Deller. 1997. Public infrastructure in economic development and growth: Evidence from rural manufacturers. Journal of the Community Development Society 28, 2: 149-69.

Hart, Stuart L., Daniel R. Denison, and Douglas A. Henderson. 1989. A contingency approach to firm location: The influence of industrial sector and level of technology. Policy Studies Journal 17, 3: 599-623.

Headey, Bruce. 1993. An economic model of subjective well-being: Integrating economic and psychological theories. Social Indicators Research 28: 97-116.

Heaton, Tim B., William B. Clifford, and Glenn V. Fuguitt. 1981. Temporal shifts in the determinants of young and elderly migration in nonmetropolitan areas. Social Forces 60, 1: 41-60.

Heubusch, Kevin. 1998. Small is beautiful. American Demographics 20, 1: 43-49.

Jeffres, Leo W., and Jean Dobos. 1995. Separating people's satisfaction with life and public perceptions of the quality of life in the environment. Social Indicators Research 34: 181-211.

Kahley, William J. 1991. Population migration in the United States: A survey of research. Economic Review-Federal Reserve Bank of Atlanta 76, 1: 12-21.

Keith, John, and Christopher Fawson. 1995. Economic development in rural Utah: Is wilderness recreation the answer? Annals of Regional Science 29, 3: 303-13.

Kusmin, Lorin D. 1994. Factors associated with the growth of local and regional economics: A review of selected empirical literature. Washington, DC: Economic Research Service, U.S. Department of Agriculture.

Liu, Ben-Chieh. 1976. Quality of life indicators in U.S. metropolitan areas: A statistical analysis. New York: Praeger. 
Michalos, Alex C. 1997. Migration and the quality of life: A review essay. Social Indicators Research 39: 121-66.

Porell, Frank W. 1982. Intermetropolitan migration and quality of life. Journal of Regional Science 22, 2: 137-58.

Reichert, Christiane Von, and Gundars Rudzitis. 1992. Multinomial logistic models explaining income changes of migrants to high-amenity counties. Review of Regional Studies 22, 1: 25-42.

Roback, Jennifer. 1982. Wages, rents, and the quality of life. Journal of Political Economy 90, 6: 1257-77.

Rogerson, R., A. Findlay, A. Morris, and M. G. Coombes. 1989. Indicators of quality of life: Some methodological issues. Environment and Planning A 21: 1655-66.

Romney, David M., Roy I. Brown, and Prem S. Fry. 1994. Improving the quality of life: Prescriptions for change. Social Indicators Research 33: $237-72$

Rosen, Sherwin. 1979. Wage-based indexes of urban quality of life. In Current issues in urban economics, Peter Mieszkowski and Mahlon Straszheim, eds. Baltimore, MD: Johns Hopkins University Press.

Rudzitis, Gundars, and Harley E. Johansen. 1991. How important is wilderness? Results from a United States survey. Environmental Management 15, 2: 227-33.

Shye, Samuel. 1989. The systemic life quality model: A basis for urban renewal evaluation. Social Indicators Research 21: 343-78.

SSID. 1993. How to use the quality-of-life index. Site Selection and Industrial Development 38, 4: 970-71.

Szalai, Alexander. 1980. The meaning of comparative research on the quality of life. In The quality of life: Comparative studies, Alexander Szalai and Frank M. Andrews, eds. London: Sage.

Wheeler, Robert J. 1991. The theoretical and empirical structure of general well-being. Social Indicators Research 24: 71-79.

Wong, Cecilia. 1998. Determining factors for local economic development: The perception of practitioners in the north west and eastern regions of the UK. Regional Studies 32, 8: 707-20.

Wood, Linda A., and Julia Johnson. 1989. Life satisfaction among the rural elderly: What do the numbers mean? Social Indicators Research 21: 379-408.

\section{ANNOTATED REFERENCE LIST}

\section{A. Quality of Life in General}

001. Andrews, Frank M. 1991. Stability and change in levels and structure of subjective well-being: USA 1972 and 1988. Social Indicators Research 25: 1-30.

Similar measures of subjective well-being were administered to representative samples of the U.S. adult population in 1972 and 1988. Measures included that of global well-being and that of specific life concerns. Results showed the structure of these measures remained stable over the sixteen-year period. However, changes in the level of some of the measures were observed, some general throughout the population, others only for certain groups.

002. - 1980. Comparative studies of life quality: Comments on the current state of the art and some issues for future research. In The quality of life: Comparative studies, Alexander Szalai and Frank M. Andrews, eds. London: Sage. A general discussion of comparative research on quality of life. Four types of information (amounts, distributions, relationships, and structures) relevant for research on quality of life are identified. Moving beyond the distinction between objective and subjective indicators of quality of life, the author presents some methodological and pro- cedural issues involved in comparative research, in particular the stability of meaning across the compared groups. Also stressed is the need for research on the causes and effects of varying levels of life quality.

003. Bunge, Mario. 1975. What is a quality of life indicator? Social Indicators Research 2: 65-79.

This theoretical discussion presents indicators as symptoms of some condition. A set of mathematically formulated definitions leads to the concept of quality-of-life indicators. The latter are not social indicators in a strict sense, since physical, psychological, social, and cultural dimensions of well-being are taken into account. To improve knowledge of the quality of life, the author calls for more research on theoretical and methodological aspects of the subject rather than an increase in the amount of related studies.

004. Burgess, J., M. Limb, and C. M. Harrison. 1988. Exploring environmental values through the medium of small groups: 1 . Theory and practice. Environment and Planning $A$ 20, 3: 309-26.

In-depth small-group research techniques are gaining recognition in the field of cultural geography. This article discusses principles, methodological issues, and interpretive strategies involved in this technique. It also presents findings from the Greenwich Open-Space Project and descriptions of landscape experiences by local people.

005. Cutter, Susan L. 1985. Rating places: A geographer's view on quality of life. Washington, DC: Association of American Geographers/Library of Congress.

This book proposes a geographical definition of quality of life that incorporates the concept of individual well-being but focuses on places rather than individuals. Because few studies use a holistic approach to the measurement of quality of life, the conceptual model includes three dimensions of quality of life: social, environmental, and perceptual. The author reviews studies that rank places in the United States and warns readers against the indiscriminate use of such studies.

006. Diener, Ed, and Eunkook Suh. 1997. Measuring quality of life: Economic, social, and subjective indicators. Social Indicators Research 40: 189-216.

Strengths and weaknesses of social indicators and measures of subjective well-being are discussed. These two alternative indicators add substantial information to the currently favored economic indicators. Consequently, the authors call for an integration of economic, social, and subjective indicators to better assess quality of life and make informed policy decisions.

007. Dorsey, Steven D., John M. Hill, and M. E. Woods. 1989. The human development spectrum: Sub-spectra and social indicators for use in development project planning, design, and implementation. Social Indicators Research 21: 93-110.

From the perspective of international development in the less developed countries, this article describes a spectrum 
of human development with seven components: needs, resources, technology, social conscience, integrity, attitude, and problem solving. An analysis of each subspectrum should be the basis for adapting project design to the appropriate level of human development, so participants are given the opportunity to progress within each subspectrum.

008. Evans, David R. 1994. Enhancing quality of life in the population at large. Social Indicators Research 33: 47-88.

This comprehensive article deals with definitional and measurement issues of quality of life. Also presented is a taxonomy of measures of quality of life, as well as factors that have an impact on quality of life. Derived from his synthesis of the quality-of-life literature, the author's theory of quality of life is multidimensional. The article concludes with a presentation of programs that enhance quality of life, according to the orientation of the program and the mode of program delivery.

009. Eyles, John. 1990. Objectifying the subjective: The measurement of environmental quality. Social Indicators Research 22: 139-53.

This article outlines the problems of measuring perceived environmental quality and stresses the differences that exist between lay and expert perceptions, especially in the case of neighborhood quality. It also reviews the methods used to assess environmental or landscape quality. The author identifies linkages between environmental quality and quality-of-life research and argues that they may be regarded as different sides of the same coin.

010. Falkenberg, Andreas W. 1998. Quality of life: Efficiency, equity and freedom in the United States and Scandinavia. Journal of Socio-Economics 27, 1: 1-27.

This article discusses three elements of quality of life (social equity, efficiency, and freedom) and how two cultures (those of the United States and Scandinavia) view these three elements. The author argues that social equity drives efficiency and freedom.

011. Harper, Wilmer M., and Luther G. Tweeten. 1977. Sociopsychological measures of quality of rural life: A proxy for measuring the marginal utility of income. American Journal of Agricultural Economics 59, 5: 1000-1005.

This article attempts to merge equity and efficiency in economic science using the marginal utility of income. A quality-of-life index is constructed as the weighted summation of three sociopsychological subindexes: alienation, worry, and self-esteem. Because the quality of life that the individual perceives is, at least in part, a function of income, the quality-of-life index is regressed on income and other variables using data from a sample of rural households. Policy implications of the declining marginal utility of income are explored.

012. Headey, Bruce. 1993. An economic model of subjective well-being: Integrating economic and psychological theories. Social Indicators Research 28: 97-116.
This article compares economic theories of welfare with psychological theories of well-being. An integrative framework (i.e., an account of human well-being) estimates the overall well-being of household members based on economic and psychological stocks and psychic income flows. Using data from the Australian Quality of Life Panel Survey, the author illustrates how the proposed model can be used.

013. Mallard, Allison G. C., Charles E. Lance, and Alex C. Michalos. 1997. Culture as a moderator of overall life satisfaction: Life facet satisfaction relationships. Social Indicators Research 40, 3: 259-84.

Using data on college students' well-being based on samples from different countries, this empirical research evaluates three models of relationships between overall satisfaction and life facet satisfaction: bottom-up, topdown, and bidirectional. The latter model performed better than the former two. An investigation showed that culture appeared to have a moderating effect on these relationships.

014. Mastekaasa, Arne, and Stein Kaasa. 1989. Measurement error and research design: A note on the utility of panel data in quality of life research. Social Indicators Research 21: 315-35.

This article discusses various strategies for dealing with measurement error in empirical research on psychological well-being. Drawing ideas from the econometrics literature, the authors suggest that efforts to limit measurement error should not be limited to improving measurement, but also include alternative research designs, in particular longitudinal (within subjects) versus cross-sectional (between subjects) approaches. The suggested panel approach is applied to the study of the subjective well-being of cancer patients.

015. Mullis, Randolph J. 1992. Measures of economic well-being as predictors of psychological well-being. Social Indicators Research 26: 119-35.

This empirical research uses psychological well-being as a single indicator of quality of life. Performances of measures of economic well-being (i.e., a comprehensive measure based on permanent income, net worth, and household economic demands) versus a conventional measure (current income) are compared as predictors of psychological well-being. Results show the former performed better than the latter in explaining the variance of psychological well-being.

016. Ouelette-Kuntz, Hélène. 1990. A pilot study in the use of the Quality of Life Interview Schedule. Social Indicators Research 23, 3: 283-98.

This study uses the Quality of Life Interview Schedule to measure the quality of life of adults affected by a mental disability. Refinements introduced in this approach proved to be acceptable to informants, and correlations of intra- and interrater agreement for the majority of scores were high. 
017. Parmenter, Trevor R. 1994. Quality of life as a concept and measurable entity. Social Indicators Research 33: 9-46.

This article deals with the concept of quality of life as applied to the domain of health. The author emphasizes the multidimensional aspects of the concept and discusses methodological issues involved in measuring the quality of life of patients, as well as ethical issues. A closer partnership between instrument developers and those being assessed is recommended.

018. Poloma, Margaret M., and Brian F. Pendleton. 1990. Religious domains and general well-being. Social Indicators Research 22: 255-76.

This study deals with religiosity and its effect on quality of life. Subjective perceptions of well-being are measured and form eleven domains, one of them being religion. Because religious dimensions strongly accounted for well-being, the authors suggest that religiosity be included in future studies of quality of life.

019. Rice, Robert W., Michael R. Frome, and Dean B. McFarlin. 1992. Work-nonwork conflict and the perceived quality of life. Journal of Organizational Behavior 13, 2: 155-68.

This study explores relationships between work-family and work-leisure conflict, and job, family, leisure, and global life satisfaction. Based on a probability sample of U.S. workers, path analyses showed that direct paths between work-nonwork conflict and global life satisfaction were not significant whereas indirect paths—via job satisfaction and leisure satisfaction-were.

020. Romney, David M., Roy I. Brown, and Prem S. Fry. 1994. Improving the quality of life: Prescriptions for change. Social Indicators Research 33: 237-72.

This article, which summarizes points made in articles from the same issue of Social Indicators Research, considers policies and practices for improving the quality of life of people in general, especially the quality of life of those individuals afflicted with a disability. The emphasis is placed on education, especially health promotion, and self-worth. Also discussed are issues related to normalization, cultural differences, cost-effectiveness, community support, individual variability, environmental opportunity, modern technology, active citizenship, and policy making.

021. Shye, Samuel. 1989. The systemic life quality model: A basis for urban renewal evaluation. Social Indicators Research 21: 343-78.

A conceptual framework is developed to observe the effectiveness of individuals' functioning. The framework is based on two facets: a subsystem of functioning facet (personality, physical, social, and cultural) and a functioning mode facet (expressive, adaptive, integrative, and conservative). The two facets result in sixteen observable content areas. Validity and reliability issues of this systemic quality- of-life model are discussed.
022. Streeten, Paul. 1995. Human development: The debate about the index. International Social Science Journal 143, 1: 25-37.

This article discusses the UNDP's Human Development Index, which comprises the logarithm of GDP per head, literacy rates, and life expectancy at birth. The author explains why human indicators are less misleading than income per head and why human development and poverty eradication should be promoted, and stresses the differences between the means (human resource developers) and ends (humanitarians) approaches to development.

023. Szalai, Alexander. 1980. The meaning of comparative research on the quality of life. In The quality of life: Comparative studies, Alexander Szalai and Frank M. Andrews, eds. London: Sage.

The author examines the semantics of the term quality of life and discusses the meanings of the phrase "How are you?" The issues involved in research on quality of life, such as the use of social indicators, are discussed, and some reflections on quality-of-life comparability and the purposes of comparative research on quality of life are presented.

024. Wheeler, Robert J. 1991. The theoretical and empirical structure of general well-being. Social Indicators Research 24: 71-79.

This empirical study uses the General Well-Being Questionnaire, based on statements evaluated with a Likert-type scale, to measure quality of life. Contributors to general well-being were grouped into seven factors including thirty variables. Results of multivariate procedures suggest the use of the self-report questionnaires to measure the quality-of-life concept.

025. Wood, Linda A., and Julia Johnson. 1989. Life satisfaction among the rural elderly: What do the numbers mean? Social Indicators Research 21: 379-408.

This article uses quantitative and qualitative data to explore the quality of life of elderly people. Results from the qualitative study were found to be similar to the scale values. However, several discrepancies across respondents and domains suggest that scale values used in quantitative approaches to the study of quality of life are of limited utility and should be considered supplementary to qualitative approaches.

\section{B. Quality of Life and Places}

026. Audirac, Yvonne, Anne H. Shermyen, and Marc T. Smith. 1990. Ideal urban form and visions of the good life: Florida's growth management dilemma. Journal of the American Planning Association 56, 4: 470-82.

This article examines Florida's growth management policies as ways to achieve an ideal urban form that is more fiscally efficient and compact yet livable. The article contends that policies encouraging compact development are based on the imagery of urban utopias and the assumption of containing urban sprawl as a key to a better quality of life. 
However, residential preference surveys reveal that many people prefer low-density lifestyles.

027. Baldassare, Mark, and Georjeanna Wilson. 1995. More trouble in paradise: Urbanization and the decline in suburban quality-of-life ratings. Urban Affairs Review 30, 5: 690-708.

This study is an empirical test of the relationship between quality of life and urbanization. Analysis of data from 1982 and 1991 surveys of a suburban region experiencing urbanization in California shows a reduction in perceived quality of life, with density and growth rate as significant predictors of quality of life over time.

028. Berger, Mark C., and Glenn C. Blomquist. 1988. Income, opportunities, and the quality of life of urban residents. In Urban change and poverty, Michael G. H. McGeary and Laurence E. Lynn, Jr., eds. Washington, DC: National Academy Press.

This book chapter focuses on the economic well-being of urban residents. Using 1980 census data, the authors compute economic statistics for large metropolitan areas. A hedonic framework is used to demonstrate that wage differences can be explained by differences in the characteristics of workers, jobs, and location. A quality-of-life index is created from location-specific amenity values, which derive from compensating differences in wages and housing prices.

029. Blomquist, Glenn C., Mark C. Berger, and John P. Hoehn. 1988. New estimates of quality of life in urban areas. American Economic Review 78, 1: 89-107.

The authors provide quality-of-life rankings both across and within urban areas for 253 counties. The authors use a national hedonic model incorporating variation in both wages and housing expenditures to derive amenity values. Amenity data encompass climatic, environmental, and urban conditions. A quality-of-life index is constructed using amenity values. The difference between the top- and bottom-ranked counties is valued at $\$ 5,146$ per household per year.

030. Burnell, James D., and George Galster. 1992. Quality-of-life measurements and urban size: An empirical note. Urban Studies 29, 5: 727-35.

This article compares the values derived from two approaches to measure quality of life-the livability comparisons approach and the market/resident approach-as they relate to urban area population sizes. Results show radically different patterns (inverse $U$ vs. straight line with a negative slope) between the two methods, suggesting little progress on the issue of optimal urban size. The authors recommend improving empirical applications of the market/resident approach, which is theoretically superior to the livability comparisons approach.

031. Cicerchia, Annalisa. 1999. Measures of optimal centrality: Indicators of city effect and urban overloading. Social Indicators Research 46: 273-99.
Optimal centrality represents a trade-off between city effect (access to superior services and opportunities due to large urban settlements) and decreased livability (due to excess concentration). This article reports on the building process of measures-mostly based on social indicators-of the concept of optimal centrality in four European countries.

032. - 1996. Indicators for the measurement of the quality of urban life: What is the appropriate territorial dimension? Social Indicators Research 39: 321-58.

By drawing on experiences in Canada and Italy, this article discusses the urban dimension as a territorial point of reference of quality-of-life indicators. Concepts such as land supply and demand and critical population mass are used to introduce an initial set of objective and subjective planning-oriented indicators of quality of life, as well as to stimulate further research.

033. Clark, David E., and James R. Kahn. 1988. The social benefits of urban cultural amenities. Journal of Regional Science 28, 3: 363-77.

A two-stage hedonic approach is used to estimate willingness to pay for urban cultural amenities such as museums, theater, dance, instrumental music, and zoos. For a typical city, the marginal benefits from improving these cultural goods are estimated to be in the $\$ .85$ to $\$ 57.9$ million range for an additional theater and an additional zoo, respectively.

034. Crider, Donald M., Fern K. Willits, and Conrad L. Kanagy. 1991. Rurality and well-being during the middle years of life. Social Indicators Research 24: 253-68.

This study is about the quality of life-as it relates to their place of residence-of a panel of people surveyed in 1971 and 1984. When controlling for income, results show that rural residents expressed slightly higher levels of community satisfaction than did urban dwellers. Number of friends was a better predictor of well-being than income for rural residents, whereas the reverse was true for urban residents.

035. Davidson, William B., and Patrick R. Cotter. 1991. The relationship between sense of community and subjective well-being: A first look. Journal of Community Psychology 19, 3: 246-53.

Telephone interviews of randomly selected southeastern U.S. residents were conducted to evaluate the relationship between subjective well-being and sense of community. The three-facet model of quality of life (happiness, worrying, and personal coping) was operationalized with a sense-of-community scale. Partial regression coefficients showed a significant relation between subjective well-being (happiness in particular) and sense of community.

036. Flower, Patrick C., and Wade R. Ragas. 1994. The effects of refineries on neighborhood property values. Journal of Real Estate Research 9, 3: 319-38. 
The effects of locational preferences, environmental events, and property location on property values are examined in a Louisiana town where two refineries are located. No significant locational differences were found from 1979 to 1991 . The only exception was for the west side of one refinery, which experienced a fire and had inadequate buffering on that side. The authors note the mitigating effect of buffering when concerns over the environmental health hazards of refineries are raised.

037. Garoogian, Rhoda, and Andrew Garoogian, eds. 1994. America's top rated small cities: A statistical handbook. Boca Raton, FL: Universal Reference.

Selected based on rankings in several national magazine surveys, a statistical profile of the sixty best U.S. cities for business and living is presented. "Small cities" refers to populations in the twenty-five thousand to one hundred thousand range. Statistical data include but are not limited to municipal finances, employment, transportation, housing, health care, education, recreation, and air quality.

038. Giannias, Dimitrios A. 1997. Quality of life structural analysis. Journal of Environmental Management 49, 2: 157-66.

A structural approach to hedonic equilibrium models is used to estimate a quality-of-life ranking of five cities in the United States. Quality-of-life is a function of housing and neighborhood characteristics (number of rooms, air quality, and travel time to work), and of city-wide amenities. Resulting quality-of-life values and rankings are different from those implied by previous work.

039._ 1996. Quality of life in southern Ontario. Canadian Journal of Regional Science 19, 2: 213-23.

A structural approach to hedonic equilibrium models is used to estimate a quality-of-life ranking of six cities in Ontario. The amenity vector is based on variables related to housing conditions, air quality, temperature, and crime. The model permits one to examine the effect of changes in the distribution of housing characteristics on ranking. The city of Guelph had the highest quality-of-life ranking.

040. Gill, Alison M. 1991. An evaluation of socially responsive planning in a new resource town. Social Indicators Research 24: 177-204.

This article examines the application of socially responsive planning to estimate its impact on community satisfaction in a new Canadian resource town. Using a quantitative approach and a qualitative approach, the study concludes that social aspects of the new community are viewed as satisfactory, but the economic health of the mining company has negative impacts on community satisfaction. The author argues that planners' inability to fully implement their ideas has resulted in a community not really different from other resource towns.

041. Greenberg, Michael, Dona Schneider, and Daiwoo Choi. 1994. Neighborhood quality. Geographical Review 84, 1: 1-15.

A survey of households in a heavily industrialized, mixed-income and mixed-race area of Philadelphia is conducted to examine the multiple-hazard-degradation hypothesis. The study finds that multiple hazards, and especially crime, have a negative impact on overall perception of neighborhood quality. Respondents who rated the area as good characterized their previous neighborhood as poor.

042. Gyourko, Joseph. 1991. How accurate are quality-of-life rankings across cities? Business Review-Federal Reserve Bank of Philadelphia (March-April): 3-14.

Amenity values are estimated using differential models of conditions affecting local land prices and wages. These conditions are assumed to be the quality of local amenities, the quality of publicly provided services, and a series of local taxes. Quality-of-life index values as well as city rankings are derived. The author cautions that the estimation of amenity prices is imprecise. Therefore, only top- and bottom-ranked cities should be compared on the basis of these estimates.

043. Gyourko, Joseph, and Joseph Tracy. 1991. The structure of local public finance and the quality of life. Journal of Political Economy 99, 4: 774-806.

This study uses a hedonic approach to derive qualityof-life rankings but focuses on the role of local fiscal conditions. Contrary to climatic characteristics, local governments can control fiscal ones and, hence, have an influence on the local quality of life. To improve quality-of-life estimates, the authors suggest the use of more encompassing data on city characteristics and better controls for worker and housing quality.

044. Herzog, Henry W., Jr., and Alan M. Schlottmann. 1993. Valuing amenities and disamenities of urban scale: Can bigger be better? Journal of Regional Science 33, 2: 145-65.

Based on a hedonic approach, this study uses a model that estimates willingness to pay and implicit, urban scale dependent amenity market prices. Results show urban markets for amenities are most probably not in a state of equilibrium, and that, based on willingness-to-pay estimates, residents within cities below 4.4 million population enjoy a net amenity situation, which should discourage out-migration from these cities.

045. Hesselbein, Frances, Marshall Goldsmith, Richard Beckhard, and Richard F. Schubert, eds. 1998. The community of the future. San Francisco: Jossey-Bass.

A group of distinguished contributors discuss the issue of quality of life in future communities. The contributors examine trends shaping the evolution of communities, as well as global dimensions and values of communities. The impact of new communication technologies on communities is debated, and ways to reinforce the social fabric of communities are discussed.

046. Heubusch, Kevin. 1997. The new rating guide to life in America's small cities. 2d ed. Amherst, NY: Prometheus Books.

This guide deals with micropolitan alternatives to metropolitan areas: a central city of at least fifteen thousand residents and a surrounding county of at least forty thousand residents (central city included). Numerical values are 
assigned to the following categories: climate/environment, diversions, economics, education, community assets, health care, housing, public safety, transportation, and urban proximity. Quality-of-life rankings are derived for the 219 identified micropolitan areas.

047. Hoehn, John P., Mark C. Berger, and Glenn C. Blomquist. 1987. A hedonic model of interregional wages, rents, and amenity values. Journal of Regional Science 27, 4: 605-20.

This article attempts to clarify the role of wages and rents in an interregional hedonic analysis of amenity values. The analytical model captures essential features from previous work but also includes an interregional location, multimarket component. Results show important differences in housing prices and wages arise due to amenities, and single-market differentials are unreliable indicators of amenity values in an interregional context.

048. Jeffres, Leo W., and Jean Dobos. 1995. Separating people's satisfaction with life and public perceptions of the quality of life in the environment. Social Indicators Research 34: 181-211.

Based on three surveys, this empirical research assesses the relationship between perceived quality of life and ascriptive, achievement, and life cycle factors. The study distinguishes two sequences relating domains to perceived quality of life: perceived quality of life of metro area and one's satisfaction with life. Results confirm bivariate relationships between factors and between domain assessments and global quality-of-life measures. However, the relationship between personal and environmental domains received little support.

049. Joseph, A. E., B. Smit, and G. P. McIlravey. 1989. Consumer preferences for rural residences: A conjoint analysis in Ontario, Canada. Environment and Planning A21, 1: 47-63.

This study uses conjoint analysis to characterize consumer preferences for different types of rural residences in southern Ontario. A survey of potential homebuyers shows they are primarily looking for privacy (medium to large lots in isolated locations). This tends to result in low-density development. Although limited, there seem to be opportunities to enhance village locations' attractiveness to consumers.

050. Liu, Ben-Chieh. 1976. Quality of life indicators in U.S. metropolitan areas: A statistical analysis. New York: Praeger.

A seminal work on the estimation of quality of life in urban areas in the United States. The author uses secondary data for 123 factors and variables measured through five components (economic, political, environmental, health and education, and social) to build an objective measure of quality of life. Using an adjusted standardized additive method to construct indicators, and an equal weighting scheme, 243 Standard Metropolitan Statistical Areas were divided into three size groups and given quality-of-life ratings for the five model components.
051. Morris, A., A. Findlay, R. Paddison, and R. Rogerson. 1989. Urban quality of life and the north-south divide. Town and Country Planning 58, 7-8: 207-11.

Britain's intermediate cities are ranked according to their quality of life. The rankings are established based on (1) a national opinion survey that identified and weighed the urban characteristics that people consider in choosing where to live and (2) secondary data on these characteristics. Results indicate the highest quality of life is available in cities in the west and north of the country. These results raise questions about the traditional north-south divide and regional development options.

052. O'Brien, David J., and Stephen Ayidiya. 1991. Neighborhood community and life satisfaction. Journal of the Community Development Society 22, 1: 21-37.

Using a random sample survey of metropolitan area residents, this research examines the impact of neighborhood community on a person's overall life satisfaction. Results show the feeling of being part of a neighborhood community is a significant variable through which other perceptions of neighborhood conditions affect the resident's perceived quality of life.

053. Roback, Jennifer. 1988. Wages, rents, and amenities: Differences among workers and regions. Economic Inquiry 26 (January): 23-41.

Using a hedonic approach, this article explains regional earnings differences by regional differences in amenities. Two types of workers are introduced, and it is demonstrated that the wage of one type of worker depends on the preferences of the other. Also, because results show utility income (including amenities) is equalized across regions, the author argues that the appropriate notion of income is actually utility income.

054. 1982. Wages, rents, and the quality of life. Journal of Political Economy 90, 6: 1257-77.

In this seminal work, the value of nonmarketable amenities is reflected in both the wage gradient and the rent gradient of a given location. The empirical work shows regional wage differences can be explained significantly by these local attributes. Using site price data, implicit prices are estimated and quality-of-life rankings for U.S. cities are derived.

055. Rogerson, R., A. Findlay, A. Morris, and M. G. Coombes. 1989. Indicators of quality of life: Some methodological issues. Environment and Planning A 21: 1655-66.

This study combines objective and subjective indicators to produce quality-of-life estimates and rankings of British cities. A national opinion survey collected information on the relative importance of quality-of-life dimensions. Values for objective indicators were obtained from published sources. Objective scores were weighted by subjective ones to produce an estimate of quality of life for each city. Weighted- and unweighted-derived rankings were compared. 
056. Rosen, Sherwin. 1979. Wage-based indexes of urban quality of life. In Current issues in urban economics, Peter Mieszkowski and Mahlon Straszheim, eds. Baltimore, MD: Johns Hopkins University Press.

In this seminal work, a quality-of-life index of urban amenities is computed from wage data. Implicit amenity price weights are obtained by regressing real wages on indicators of amenities after controlling for personal productivity differences. Five major groups of city attributes are distinguished: pollution, climate, crime, crowding, and market conditions. Estimates are based on 1970 data from the Current Population Survey.

057. Sauvageau, David, and Geoffrey Loftus. 1998. Places rated almanac: Your guide to finding the best places to live in North America. 5th ed. New York: Macmillan.

This guide uses five categories of facilities (transportation, education, arts, health care, and recreation) and four categories of indicators (cost of living, jobs, climate, and crime) to rank 351 metropolitan areas in Canada and the United States. Factor analysis is used to determine the most appropriate variables for scoring. For each category, scores range from 0 to 100 and are normalized such that the 50 th percentile is the average for all metro areas.

058. Schwirian, Kent P., Amy L. Nelson, and Patricia M. Schwirian. 1995. Modeling urbanism: Economic, social and environmental stress in cities. Social Indicators Research 35: 201-23.

This article empirically shows that urbanism is a multidimensional construct based on demographic scale, economic stress, social stress, and environmental stress. The authors use social indicators compiled by a national nonprofit organization for 195 cities. Results also show there are causal connections between the separate dimensions within the urbanism factor, and these dimensions may be reliably measured with standard composite variables.

059. Sherwood, David H. 1993. Identifying the quality of life in your community: Quality of life indicators. Plan Canada (November): 11-13.

The Canada Mortgage and Housing Corporation has developed a model that outlines objective indicators for measuring a community's quality of life. The model consists of four levels: (1) sectoral policies of local government, such as housing, land use, or transportation; (2) components of livability by which each sectoral policy should be evaluated (economic vitality, social well-being, and environmental integrity); (3) indicators of livability for each component of livability; and (4) specific measures (variables) for each indicator of livability.

060. Short, John R. 1989. The humane city: Cities as if people matter. Oxford: Basil Blackwell.

The author first presents cities as if people do not matter (i.e., cities that emphasize capital, professionals, and selected people). Then, the author recommends going beyond liberalism, welfarism, and the opposition between capitalism and socialism. It is argued that cities' quality of life can be improved by putting people first: residents should not be viewed as the cause of urban problems but rather as driving forces for urban quality-of-life improvement.

061. Stover, Mark Edward, and Charles L. Leven. 1992. Methodological issues in the determination of the quality of life in urban areas. Urban Studies 29, 5: 737-54.

This article examines the importance of functional form in estimating values for the quality of life in urban areas. Values of local amenities are assessed from the interaction between the labor and real estate markets. Alternative theoretical specifications are consistent with previous work but yet different. Results show quality-of-life rankings for 253 urban counties are highly sensitive to alternative model specifications.

062. Straus, Murray A., Arnold S. Linsky, and Ronet Bachman-Prehn. 1989. Change in the stressfulness of life in American states and regions from 1976 to 1982 . Social Indicators Research 21, 3: 229-57.

The authors use the State Stress Index to measure differences in the occurrence of stressful life events based on three types of indicators: economic stressors (e.g., business failures), family stressors (e.g., divorces), and other stressful events (e.g., high school dropouts). All data were obtained from published sources. States are ranked according to their index score, both in 1976 and in 1982. Results show that the United States became a more stressful society over that period, and the West remained the most stressful region in the nation.

063. Sullivan, W. C., III. 1996. Cluster housing at the rural-urban fringe: The search for adequate and satisfying places to live. Journal of Architectural and Planning Research 13, 4: 291-309.

Accommodating residential development at the rural-urban fringe poses the difficulty of preserving rural character while providing people with satisfying places to live. Cluster housing development has been proposed as a way to meet this challenge. Analysis of adequacy and satisfaction ratings by people living at the rural-urban fringe in Michigan shows that cluster development is most interesting when houses are built close and oriented to natural features.

064. Weber, Margaret J., Jacquelyn McCray, and Mikyoung Ha. 1993. Housing assessment criteria of rural households. Social Indicators Research 28: 21-43.

A sample of rural households from Arkansas and Oklahoma was used to explore factors relating to residential location. Factor analysis was used to evaluate responses to the ideal and present housing situation and indicated twenty-one factors including one hundred items loading at .50 or above. Important factors in defining characteristics of the ideal home include dwelling attributes, affordability, and water quality, followed by safety, appearance, and family spatial requirements. 
065. Weirick, William N. 1987. Amenities, factor mobility, and market prices. Land Economics 63, 3: 272-83.

This article explores the question of the accuracy of estimation of demand for amenities. A general equilibrium framework is used to study the implications of factor migration and multiple market price responses to amenity endowment change. The conclusion is that accurate willingness to pay inference is not guaranteed when multiple adjustment dimensions are open to individuals.

\section{Quality of Life and Migration}

066. Beesley, Kenneth B., and Roy T. Bowles. 1991. Change in the countryside: The turnaround, the community, and the quality of life. The Rural Sociologist 11, 4: 37-46.

This discussion first describes the patterns and trends of the population turnaround, that is, a revival of population growth in rural areas of Canada and the United States in the 1970s. Underlying factors of this migration are people's preferences for rural areas and quality-of-life considerations. Impacts of this growth on rural communities are discussed, including social patterns. Emergent research questions are outlined and relate to quality-of-life considerations and community changes.

067. Cebula, Richard J., and Richard K. Vedder. 1973. A note on migration, economic opportunity, and the quality of life. Journal of Regional Science 13, 2: 205-11.

The framework of this article is one in which the decision to migrate is treated as an investment decision: the individual chooses to migrate if there are net benefits over time from such migration. The empirical analysis relates economic, social, and environmental variables to labor migration. Results of the analysis of thirty-nine SMSAs in 1968 show that migrants appear to be interested in both explicit and implicit economic considerations when they decide to move.

068. Clark, David E., and James C. Cosgrove. 1991. Amenities versus labor market opportunities: Choosing the optimal distance to move. Journal of Regional Science 31, 3: 311-28.

This article compares the relative importance of two possible explanations for migrating between metropolitan areas: the human-capital (disequilibrium) and the hedonic (equilibrium) migration models. The empirical model tests the separate influences of the disequilibrium and the amenity components of wages on the distance of migration. Results show both economic and amenity factors are important in explaining regional migration and the distance moved.

069. Clark, David E., and William J. Hunter. 1992. The impact of economic opportunity, amenities and fiscal factors on age-specific migration rates. Journal of Regional Science 32, 3: 349-65.

This article integrates three categories of determinants of migration (economic opportunities, amenities, and fiscal factors) into a life cycle framework. A nationwide model of white male migration over ten years shows that the three types of determinants are important. In accordance with life cycle considerations, economic opportunities and income taxes are more important for younger men whereas amenities and inheritance taxes are more important for older men.

070. Clark, David E., Thomas A. Knapp, and Nancy E. White. 1996. Personal and location-specific characteristics and elderly interstate migration. Growth and Change 27, 3:327-51.

This article investigates the impact of locational and individual characteristics on elderly interstate migration. Household data are merged with measures of amenities and fiscal characteristics. A push model, a pull model, and a difference model are estimated. Results show both locational and individual characteristics are important factors in elderly persons' decision to migrate. Moreover, because the difference model provides the best overall fit, policy makers should consider relative differences in site characteristics rather than levels.

071. Currie, Raymond F., and Shiva S. Halli. 1989. Mixed motivations for migration in the urban prairies: A comparative approach. Social Indicators Research 21: 481-99.

Surveys for both the Winnipeg and the Edmonton areas were conducted in 1981 to study factors that influence the decision to migrate. In both cities, migration is associated with higher education. Economic factors were listed by respondents as the most important reasons for migration, followed by family reasons and educational opportunities.

072. Graves, Philip E. 1983. Migration with a composite amenity: The role of rents. Journal of Regional Science 23, 4: 541-46.

This article uses an equilibrium approach to explain white net in-migration among 137 Standard Metropolitan Statistical Areas for the years 1960-70. Unlike previous work from the same author, rent alone is used as a proxy for the set of unpriced amenities that might affect migration to a given region. Regression results indicate that locations offering high rents experience net in-migration for all age groups ceteris paribus and that the rent coefficient is strongly significant.

073. - 1980. Migration and climate. Journal of Regional Science 20, 2: 227-37.

This article opposes two models of migration: disequilibrium (income and employment opportunity differentials) and equilibrium (adjustment of market rents and wages in order to leave utility constant over space). Using gross migration flows for Standard Metropolitan Statistical Areas and climate variables as indicators of location-specific nontradable goods, regression results support previous work results; that is, an equilibrium amenity approach to migration has more explanatory power.

074. _ 1979. A life-cycle empirical analysis of migration and climate, by race. Journal of Urban Economics 6: 135-47.

This article explores the migration-climate-economic opportunity relationships over the life cycle. The geo- 
graphic area units are Standard Metropolitan Statistical Areas. Results by race and life cycle indicate that migrants buy a bundle of location-specific goods, and the relative importance of economic opportunity and climatic amenities within that bundle varies by age and by income (and, hence, by race, since nonwhites have much lower incomes than whites, on average).

075. Graves, Philip E., and Donald M. Waldman. 1991. Multimarket amenity compensation and the behavior of the elderly. American Economic Review 81, 5: 1374-81.

This study tests the multimarket-amenity-compensation hypothesis that amenities are priced in both land and labor markets. Using data and results from previous work, the analysis shows that elderly behavior is consistent with model expectations: elderly persons migrate to locations where amenities are predominantly priced in labor markets. Policy implications of this result are presented.

076. Greenwood, Michael J. 1985. Human migration: Theory, models, and empirical studies. Journal of Regional Science 25, 4: 521-44.

This article discusses the changes that have occurred in recent U.S. migration patterns: the regional shift and the rural-urban migration turnaround. It also presents the current understanding of these changes. The author reviews the determinants of migration, including life cycle considerations, migration in equilibrium versus disequilibrium systems, and micro analyses. The author concludes by discussing the developments made possible by the availability of time-series data on migration.

077. Haigood, Traci L., and John L. Crompton. 1998. The role of recreational amenities in retiree relocation decisions. Journal of Park and Recreation Administration 16, 1: 25-45.

The authors review the literature on retirees' motivations to relocate and the amenities that make an area attractive to retirees. The article then focuses on a survey in which retirees from five Texas communities were asked about their decision to relocate. Results show the desire to leave colder climates and to live closer to various recreational opportunities in a more aesthetically pleasing area are significant factors in a retiree's decision to relocate.

078. Heaton, Tim B., William B. Clifford, and Glenn V. Fuguitt. 1981. Temporal shifts in the determinants of young and elderly migration in nonmetropolitan areas. Social Forces 60, 1: 41-60.

An empirical analysis of the determinants of young and elderly net migration rates for nonmetropolitan areas over three time periods yields several conclusions. In particular, economic factors are more important determinants of migration for the young than for the elderly; the reverse is true for noneconomic factors. Also, as the standard of living rises, more people become willing to trade off monetary benefits for amenity-related qualities at their place of residence.

079. Heubusch, Kevin. 1998. Small is beautiful. American Demographics 20, 1: 43-49.
The author defines micropolitan areas, where one in twenty Americans lives, as small cities located beyond congested metropolitan areas. These small cities offer city benefits (job opportunities, cultural activities, urban services, and proximity to countryside) without the inconveniences of large-scale cities (crime, stress, traffic, and high property taxes). The 193 micropolitan areas are influenced by metropolitan population trends. Some of them grow faster than fast-growing metropolitan areas.

080. Jacob, Jeffrey C. 1996. The North American back-tothe-land movement. Community Development Journal 31, 3: 241-49.

Over the past three decades, an urban-to-rural migration has occurred. A portion of this movement was composed of back-to-the-landers, well-educated urban residents who moved to rural areas to practice semisubsistence agriculture. Based on a national survey, this article finds that back-to-the-landers hold progressive views on environmental and social issues, but the likelihood that they join their neighbors in community development and activist projects is much lower.

081. Kahley, William J. 1991. Population migration in the United States: A survey of research. Economic ReviewFederal Reserve Bank of Atlanta 76, 1: 12-21.

The author reviews the literature on migration theories and migration in regional growth and development models, as well as the determinants of migration: personal characteristics and place characteristics. The author also presents unresolved issues in migration research, such as asymmetries between in- and out-migration, data limitations, and model specifications. Finally, policy implications of the research results are outlined.

082. Liu, Ben-Chieh. 1975. Differential net migration rates and the quality of life. Review of Economics and Statistics 57, 3: 329-37.

The relationships between the variations in net migration rates among states and the levels of quality of life measured in those states are explored. Quality of life is assessed via indexes for a nine-component model comprising more than one hundred variables. The decision to migrate is assumed to follow a quality-of-life maximization behavior. Regression results show net migration rates between 1960 and 1970 responded positively to the overall quality-of-life indexes. Economic pursuits play only a secondary role.

083. Mathur, Vijay K., and Sheldon H. Stein. 1991. A dynamic interregional theory of migration and population growth. Land Economics 67, 3: 292-98.

This article attempts to integrate migration theory and the theory of regional amenity value determination into a cohesive theoretical model. Several adjustments are made to Roback's (1982) theoretical framework. Comparative statics results and implications of the model are discussed. In particular, the fact that the authors' model shows that migration, population, earning, rents, and amenities are jointly dependent variables raises questions about the validity of single-equation ordinary least squares estimates. 
084. Michalos, Alex C. 1997. Migration and the quality of life: A review essay. Social Indicators Research 39: 121-66.

This article provides a review of research for the past thirty years on the relationships between migration and the quality of life broadly construed. First, migration or residential mobility studies are discussed around five lines of enquiry. Then, an overview of migration studies is given. Finally a list of critical issues in quality-of-life measurement is presented.

085. Nord, Mark, and John B. Cromartie. 1997. Migration: The increasing importance of rural natural amenities. Choices (3rd quarter) 12: 22-23.

Rural population gains have risen steadily during the late 1980s and early 1990s. The authors describe three phases of rural comparative advantage. Recent rural growth has confirmed the importance of residential, recreational, and natural amenities, as well as rurality itself. This signals new opportunities for rural development, since communities can enhance their natural amenities and increase their residential desirability.

086. Porell, Frank W. 1982. Intermetropolitan migration and quality of life. Journal of Regional Science 22, 2: 137-58.

This article uses a generalized systemic gravity model of migration to assess the relative impacts of economic and quality-of-life factors as determinants of migration. A sample of twenty-five Standard Metropolitan Statistical Areas was used to estimate this model for the years 1965-70. Results show quality-of-life factors had a significant impact on in-migration, but the long-run equilibrium thesis of migration was not supported.

087. Reichert, Christiane Von, and Gundars Rudzitis. 1992. Multinomial logistic models explaining income changes of migrants to high-amenity counties. Review of Regional Studies 22, 1: 25-42.

Amenities are increasingly recognized as important reasons for people to migrate. This study is based on a survey of fifteen high-amenity U.S. counties. Nearly half of all surveyed migrants to these counties received lower incomes. Also, significant relationships were found between type of migrant, reasons for migration, and probability of income loss. Amenities appear to be assets for nonmetropolitan county growth.

\section{Quality of Life and Firm Location}

088. Appold, Stephen J. 1991. The location process of industrial research laboratories. Annals of Regional Science 25, 2: 131-44.

The location decision process of industrial research laboratories is inferred via their location. The analysis reveals that laboratories tend to imitate each other as they are clustered in similar local environments. These location patterns are hypothesized to reflect not actual preferences and constraints but rather uncertainty about the hospitality of the potential location.
089. Blair, John P., and Robert Premus. 1987. Major factors in industrial location: A review. Economic Development Quarterly 1, 1: 72-85.

Industrial location choices are influenced to a lesser extent than in the past by traditional factors such as access to markets and raw materials. With a shift to an advanced-technology-based economy, and while still being more significant in terms of overall influence, these factors are now part of a longer list including nontraditional factors, such as local taxes and education, that are gaining in importance. This suggests alternative industrial development policies that should improve the overall locational attractiveness of regions.

090. Conway, McKinley. 1991. Quality-of-life factors must be custom-fit for both individuals and corporate units. Site Selection and Industrial Development 36 (February): 96-97.

Because people have different lifestyles, quality of life means different things to different groups. A typology can be developed that matches lifestyles with expectations. For example, middle-age employees will more likely be looking for good schools than retiring employees. When selecting a location for a facility that must accommodate a number of people, it may be helpful to classify the workforce into lifestyle groups and select the site accordingly.

091. Decker, Jill M., and John L. Crompton. 1990. Business location decisions: The relative importance of quality of life and recreation, park and cultural opportunities. Journal of Park and Recreation Administration 8, 2: 26-43.

With the shift to a service-based economy, the criteria businesses use in deciding where to locate have changed. Recreational, park, and cultural amenities have become important to corporations that look for attractive community characteristics for their employees. However, aspects other than quality of life and access to leisure opportunities matter.

092. Foster, Robert. 1977. Economic and quality of life factors in industrial location decisions. Social Indicators Research 4: 247-65.

This study is based on a questionnaire sent to firms operating in various industries in Canada and the United States in the mid 1970s. The questionnaire dealt with economic variables and quality-of-life factors within a location decision context, asking also for trade-offs between the two determinants. Results indicate both factors are important in the site selection process. Firms would not trade off distance to markets and availability of skilled workers.

093. Gottlieb, Paul D. 1994. Amenities as an economic development tool: Is there enough evidence? Economic Development Quarterly 8, 3: 270-85.

Based on a review of the literature on amenity-oriented firm location and employment growth, this article examines arguments and evidence for the use of an amenityoriented strategy in regional economic development. The analysis suggests that researcher consider methodological 
issues more closely and makes a number of policy recommendations. In particular, communities using an amenity strategy should focus on basics such as schools, environment, crime, and traffic.

094. Halstead, John M., and Steven C. Deller. 1997. Public infrastructure in economic development and growth: Evidence from rural manufacturers. Journal of the Community Development Society 28, 2: 149-69.

A survey of two thousand small rural manufacturing firms was conducted in upper New England and Wisconsin. Firm personnel were asked to rank sixteen factors thought to influence their ability to effectively operate the firm. Amenities and quality of life received the highest rating for each of the four study states, ahead of the more traditional factors such as public infrastructure. Limited public resources should be invested in those aspects of a community that make it a pleasant place to live.

095. Hart, Stuart L., Daniel R. Denison, and Douglas A. Henderson. 1989. A contingency approach to firm location: The influence of industrial sector and level of technology. Policy Studies Journal 17, 3: 599-623.

A review of the determinants of industrial location concludes that the literature is dominated by two extremes: least cost factors and quality-of-life factors. A questionnaire was sent to 2,248 company CEOs, asking them to rate the importance of thirty-seven least cost and quality-of-life factor influences on location. Results show the most important issue is proximity to markets. But the relative importance of criteria seems to have shifted toward quality-of-life aspects, with different ratings for different industrial sectors.

096. Kohler, Hans-Peter. 1997. The effect of hedonic migration decisions and region-specific amenities on industrial location: Could Silicon Valley be in South Dakota? Journal of Regional Science 37, 3: 379-94.

This theoretical article examines the relationship between hedonic migration, regional amenities, and industrial location. Human capital dependent industries have "footloose" firms that tend to follow workers to higher amenity areas. When the amenity function is not linear, these firms differentiate into companies that follow workers completely to the most amenable locations and companies that select intermediate locations at the periphery of attractive places.

097. Lyne, Jack. 1988. Quality-of-life factors dominate many facility location decisions. Industrial Development and Site Selection Handbook 33 (August): 868-70.

Site selection decisions rely increasingly on quality-of-life factors. Forty-five percent of the corporate real estate executives responding to a survey indicated that these factors controlled both initial site screening and final selection. Overall rankings placed availability of a major airport, physical environment, and transportation systems in general at the top of the list. The relative importance of quality-of-life factors varied according to the type of facilities (e.g., headquarters vs. manufacturing).
098. Ó hUallacháin, B. 1990. The location of U.S. manufacturing: Some empirical evidence on recent geographical shifts. Environment and Planning A 22, 9: 1205-22.

This article identifies the determinants of intermetropolitan shifts in total manufacturing and selected hightechnology industries for the years 1977-84. Using Metropolitan Statistical Area data, the role of agglomeration forces, market opportunities, labor force characteristics, amenities, infrastructure, and taxation policies is evaluated. Regression analysis results indicate growth rates decrease with increasing industry concentration and metropolitan size.

099. Raitz, Karl. 1988. Advantages of place as perceived by Sunbelt promoters. Growth and Change 19, 4: 14-29.

This article evaluates the perceived importance of locational factors in attracting business migrants from the U.S. North to the U.S. South. Results of a questionnaire sent to chamber of commerce executives reveals perception variations between subareas of the South. Thus, border cities view southern cities as their major competitors whereas southern cities view other fast-growing southern cities as their major competitors.

100. SSID. 1993. How to use the quality-of-life index. Site Selection and Industrial Development 38, 4: 970-71.

The quality-of-life index provides information on eight quality-of-life factors for U.S. states and four to six factors for metropolitan areas. Its purpose is to help business location seekers assess the quality of life in state, metropolitan, and local (county) areas throughout the world. A measure tells how each state and metropolitan area compares with all other states and metropolitan areas.

\section{E. Quality of Life and Growth/Development}

101. Beale, Calvin L., and Kenneth M. Johnson. 1998. The identification of recreational counties in nonmetropolitan areas of the USA. Population Research and Policy Review 17: 37-53.

This article identifies nonmetropolitan U.S. counties in which recreational activity is an important segment of the local economy. The identification uses a multistep process combining analysis of two empirical measures of recreational activity with a review of contextual indicators. Two hundred and eighty-five counties were identified. These counties represent 12 percent of the counties and 15 percent of the 1990 nonmetropolitan population, with significant growth due mainly to in-migration.

102. Bergstrom, John C., H. Ken Cordell, Gregory A. Ashley, and Alan E. Watson. 1990. Economic impacts of recreational spending on rural areas: A case study. Economic Development Quarterly 4, 1: 29-39.

This article examines the impact of spending associated with outdoor recreation on the local economy of rural areas. Estimations were done using regional input-output models. Results show recreational spending was a significant contributor to employment, income, gross output, and value added in the selected areas. This may posit outdoor recreation as a rural economic development strategy. 
103. Blaine, Thomas W., and Golam Mohammad. 1991. An empirical assessment of U.S. consumer expenditures for recreation-related goods and services: 1946-1988. Leisure Sciences 13, 2: 111-22.

An increasing share of the consumer budget is spent on recreation-related goods and services (8 percent in 1990). The demand for recreation-related goods and services is estimated as a function of prices, income, and leisure time budgets. Results show that such a demand is relatively price inelastic but highly income and leisure time elastic.

104. Boarnet, Marlon G. 1994. An empirical model of intrametropolitan population and employment growth. Papers in Regional Science 73, 2: 135-52.

This article examines how population and employment growth patterns are distributed across a metropolitan area. The simultaneous-equation model uses data from 365 municipalities in New Jersey for the years 1980-88. With signs and significance patterns in agreement with expectations, the results support many hypotheses with regard to intrametropolitan population and employment movements.

105. Carlino, Gerald A., and Edwin S. Mills. 1987. The determinants of county growth. Journal of Regional Science 27, 1: 39-54.

This seminal work presents an analysis of the determinants of population and employment changes by county from an interregional perspective. The study uses data for the late 1970s in a simultaneous-equation framework and analyzes the effects of economic, demographic, and climate variables on these changes. Population and employment are found to be interrelated. Variables that depend on public policies seem to have little impact on either county population or total employment growth.

106. Clark, David E., and Christopher A. Murphy. 1996. Countywide employment and population growth: An analysis of the 1980s. Journal of Regional Science 36, 2: 235-56.

Following the earlier work of Carlino and Mills, this study focuses on interregional differences in population and employment growth rates. The partial adjustment model uses county-level data for the years 1981-89 and captures differences in demography, employment structure, amenities, fiscal conditions, and relative location. Feedback effects between population and employment growth are not strong.

107. Crown, William H. 1991. Migration and regional economic growth: An origin-destination model. Economic Development Quarterly 5, 1: 45-59.

This article provides answers to some of the questions raised in the debate about whether migration has a stronger effect on employment or vice versa. Two-stage least squares is used to estimate a state-level simultaneous-equation model of migration and manufacturing employment growth. Results indicate both are jointly determined, and the latter has a stronger effect on the for- mer. Results also show amenity variables are significant determinants of both employment and migration.

108. Duffy-Deno, Kevin T. 1998. The effect of federal wilderness on county growth in the intermountain western United States. Journal of Regional Science 38, 1: 109-36.

A disequilibrium model of population and employment growth is used to estimate the impact of federally owned wilderness areas on local economies in the intermountain western United States. The model uses a cross-sectional sample of county-level data for the eight states. Results show no evidence of a direct or indirect relationship between the existence of federal wilderness and either population density or total employment density growth for the years 1980-90.

109. - 1997a. Economic effect of endangered species preservation in the non-metropolitan West. Growth and Change 28 (Summer): 263-88.

This article examines the effect of the Endangered Species Act on local economies in the nonmetropolitan counties of the U.S. West. The analysis of a cross-sectional sample of county-level data is done using a four-equation, simultaneous model of regional economic development. Results show no evidence of a statistical relationship between listed species density and county employment density growth.

110. 1997b. The effect of state parks on the country economies of the West. Journal of Leisure Research 29, 2: 201-24.

The local economic impacts of state parks on nonmetropolitan counties in the intermountain U.S. West are examined. To capture both direct and indirect impacts, a disequilibrium, four-equation simultaneous model of county economic development is used. The number of state parks per acre of county land has a statistically significant and positive but small effect on both county population and employment densities.

111. Gottlieb, Paul D. 1995. The "golden egg" as a natural resource: Toward a normative theory of growth management. Society and Natural Resources 8, 1: 49-56.

This article explains the dilemma faced by North American suburbs, which demand both preservation of local amenities (to protect quality of life) and physical development (to expand the tax base). Growth management has been proposed as a policy solution to this dilemma. An analogy is made between this approach and resource economics. The author concludes that the growth management debate raises legitimate issues of sustainability and efficiency.

112. Green, Gary P., and Arnold Fleischmann. 1989. Analyzing local strategies for promoting economic development. Policy Studies Journal 17, 3: 557-73.

With the shift to a service-based economy, an increased mobility of capital, and large-scale migratory movements, U.S. cities face economic and social changes. Based on a 
survey and census data, this study examines economic development efforts by local communities. Results reveal that communities adopt various strategies and organizational structures to attract businesses.

113. Hendon, William C. 1991. The wilderness as a source of recreation and renewal: Who uses it? What are their characteristics? Their other interests? Their preferences? American Journal of Economics and Sociology 50, 1: 105-12.

The wilderness is enjoyed by people of different income groups and classes, and data from a National Endowment for the Arts survey reveal the characteristics of those people. Results distinguish between more frequent and less frequent wilderness users. The frequent users are better educated, are more likely to participate in out-of-home activities, pursue more intellectual leisure-time interests, reside in the suburbs, work as professionals, and earn more income.

114. Henry, Mark S., David L. Barkley, and Shuming Bao. 1997. The hinterland's stake in metropolitan growth: Evidence from selected southern regions. Journal of Regional Science 37, 3: 479-501.

This article tests for the presence and direction of rural-urban area linkages in functional economic areas (FEAs) of the U.S. South. A simultaneous-equation system for employment and population change is estimated. Results show rural-area population and employment grew faster than average during the years 1980-90 if the rural area was in an FEA with rapid population growth in the urban fringe and slow population growth in the urban core.

115. Izzo, George, and Arthur L. Schwartz, Jr. 1994. Calusa Trace development: Are wetlands amenities? Journal of Real Estate Literature 2, 2: 245-56.

In the St. Petersburg, Florida, area, an original development plan for thirty-six $\$ 200,000$ units later changed to twenty-two $\$ 300,000$ units resulted in the cancellation of all predevelopment purchase agreements. This case study raises questions about the marketability of wetland as a residential amenity.

116. Jepson, Edward J., Jr., David W. Marcouiller, and Steven C. Deller. 1997. CPL bibliography 338/339/340. Incorporating market and nonmarket values into regional planning for rural development. Journal of Planning Literature 12, 2: 220-57.

This annotated bibliography provides planners and policy makers with information about the main concepts and methods related to the development of resource-dependent regions, focusing on those with forest-dependent economies. The three dimensions of regional development dynamics, nonmarket valuation, and regional modeling methodologies are addressed.

117. Keith, John, and Christopher Fawson. 1995. Economic development in rural Utah: Is wilderness recreation the answer? Annals of Regional Science 29, 3: 303-13.
Because outdoor recreation may constitute a rural economic development strategy, this article uses input-output multipliers to estimate expenditures by such visitors. Data are derived from a survey of wilderness users in selected and proposed wilderness areas in Utah. Results show, with less than 1 percent of total sales in most of the counties studied, expenditures by outdoor recreation participants are not large enough to significantly influence local economies.

118. Keith, John, Christopher Fawson, and Tsangyao Chang. 1996. Recreation as an economic development strategy: Some evidence from Utah. Journal of Leisure Research 28, 2: 96-107.

This article examines nonagricultural employment patterns for the years 1973-92 for twenty-four rural counties in Utah. Data are grouped into five industry sectors: mining, manufacturing, utilities, recreation and tourism, and government. Analysis of the time-series sample indicates that the economies of tourism-dependent counties are subject to relatively large annual variances. This suggests that planners should be cautious about advocating tourism as an economic base.

119. Knapp, Thomas A., and Philip E. Graves. 1989. On the role of amenities in models of migration and regional development. Journal of Regional Science 29, 1: 71-87.

This review of the literature analyzes the role of location-specific amenities in human migration decisions and, subsequently, regional development. A taxonomy of this role is proposed based on the existence or not of producer amenities and of consumer amenities. Because regional development is largely a function of the mobility behavior of firms and households, regional futures may be better understood by studying the role of amenities as determinants of mobility behavior.

120. Kopp, Raymond J. 1992. The role of natural assets in economic development. Resources 106: 7-10.

Natural assets such as water, agricultural and forest lands, and wildlife habitats are renewable and provide goods and services into the indefinite future if well managed. This article argues that the developed world would be more successful in convincing the developing world to protect its natural assets if a plan of action were focused on enhancing those natural assets.

121. Kulshreshtha, S. N., and J. A. Gillies. 1993. Economic evaluation of aesthetic amenities: A case study of a river view. Water Resources Bulletin 29, 2: 257-66.

A hedonic price model is used to estimate the value of the Saskatchewan River to the city of Saskatoon, Canada. The analysis includes such issues as willingness to pay for increased property taxes, and parks and trails in the vicinity of the river. Because the annual dollar value of the river is assessed at $\$ 1.2$ million, the authors conclude that changes in its aesthetic qualities would affect residents' welfare.

122. Kusmin, Lorin D. 1994. Factors associated with the growth of local and regional economics: A review of selected empirical liter- 
ature. Washington, DC: Economic Research Service, U.S. Department of Agriculture.

Thirty-five empirical studies of factors influencing business location and/or regional economic growth are reviewed. Regional characteristics that have been hypothesized to affect growth are numerous and include natural amenities and regional dummy variables. Differences in methodology between the studies are described. Few results are found to be consistent across studies, since they are sensitive to study design and scope. Suggestions for future research are made.

123. Lankford, Samuel V., Al Williams, and Jill KnowlesLankford. 1997. Perceptions of outdoor recreation opportunities and support for tourism development. Journal of Travel Research 35, 3: 65-69.

This article is concerned with resident perceptions and attitudes with regard to impacts on local outdoor recreation opportunities. A survey based on 5-point Likert-type scale responses was conducted in western North America. Results of the discriminant analysis show participants who perceived an impact of tourism on outdoor recreation opportunities spent more time in such activities and felt that tourism brought negative changes such as noise and litter.

124. Myers, Dowell. 1987. Internal monitoring of quality of life for economic development. Economic Development Quarterly 1, 3: 268-78.

This article studies the case of one community, Austin, Texas, that promoted its quality of life to attract high-technology industries. Austin was so successful that it consequently experienced dramatic changes that threatened its attractiveness. The author concludes that there is a need for internal monitoring of quality-of-life local trends to ensure long-term community development.

125. Power, Thomas M. 1996. Lost landscapes and failed economies: The search for a value of place. Washington, DC: Island Press.

The author stresses the conflict between natural resource extraction and environmental protection. Empirical analysis shows that extractive industries make a smaller contribution and play a more destabilizing role in local economies than is usually assumed. On the contrary, because they can attract residents and businesses, desirable environments are likely to have an economic worth of their own. A choice needs to be made as to which should be partially sacrificed for the community's long-term interests.

126. Ready, Richard C., Mark C. Berger, and Glenn C. Blomquist. 1997. Measuring amenity benefits from farmland: Hedonic pricing vs. contingent valuation. Growth and Change 28 (Fall): 438-58.

Contingent valuation and hedonic pricing are used to estimate the monetary value of external benefits associated with the preservation of horse farms in Kentucky and enjoyed by nonfarm dwellers. The hedonic model was estimated using wage and housing equations. Data for the contingent valuation study were obtained through a mail questionnaire. Estimates generated by the two methods are within 20 percent of each other.

127. Rudzitis, Gundars, and Harley E. Johansen. 1991. How important is wilderness? Results from a United States survey. Environmental Management 15, 2: 227-33.

A national survey of residents of wilderness counties was conducted to assess their attitudes toward the management of federally designated wilderness. Survey results show a majority of the respondents agreed that the presence of wilderness was an important reason in their decision to move or to stay in the area. Both migrants and residents opposed opening wilderness areas for development.

128. Stoll, John R., John C. Bergstrom, and Lonnie L. Jones. 1988. Recreational boating and its economic impact in Texas. Leisure Sciences 10, 1: 51-67.

This article provides an estimate of the monetary benefits of recreational boating in Texas. Using a state-level input-output model, the addition of direct, indirect, and induced effects of this industry was assessed to exceed \$1.7 billion in 1983.

129. Wong, Cecilia. 1998. Determining factors for local economic development: The perception of practitioners in the north west and eastern regions of the UK. Regional Studies 32, 8: 707-20.

This article examines how policy makers perceive the importance of different factors for local economic development. Conducted in two U.K. regions, the study uses a case study approach and in-depth interviews of practitioners. Eleven traditional economic development and soft intangible factors are found. For both regions, respondents believed traditional factors had to be satisfied before more intangible factors such as quality of life could be considered to increase a community's attractiveness.

\section{INDEX BY AUTHOR}

Andrews, Frank M., 1, 2

Appold, Stephen J., 88

Ashley, Gregory A., 102

Audirac, Yvonne, 26

Ayidiya, Stephen, 52

Bachman-Prehn, Ronet, 62

Baldassare, Mark, 27

Bao, Shuming, 114

Barkley, David L., 114

Beale, Calvin L., 101

Beckhard, Richard, 45

Beesley, Kenneth B., 66

Berger, Mark C., 28, 29, 47, 126

Bergstrom, John C., 102, 128

Blaine, Thomas W., 103

Blair, John P., 89

Blomquist, Glenn C., 28, 29, 47, 126

Boarnet, Marlon G., 104

Bowles, Roy T., 66 
Brown, Roy I., 20

Bunge, Mario, 3

Burgess, J., 4

Burnell, James D., 30

Carlino, Gerald A., 105

Cebula, Richard J., 67

Chang, Tsangyao, 118

Choi, Daiwoo, 41

Cicerchia, Annalisa, 31, 32

Clark, David E., 33, 68, 69, 70, 106

Clifford, William B., 78

Conway, McKinley, 90

Coombes, M. G., 55

Cordell, H. Ken, 102

Cosgrove, James C., 68

Cotter, Patrick R., 35

Crider, Donald M., 34

Cromartie, John B., 85

Crompton, John L., 77, 91

Crown, William H., 107

Currie, Raymond F., 71

Cutter, Susan L., 5

Davidson, William B., 35

Decker, Jill M., 91

Deller, Steven C., 94, 116

Denison, Daniel R., 95

Diener, Ed, 6

Dobos, Jean, 48

Dorsey, Steven D., 7

Duffy-Deno, Kevin T., 108, 109, 110

Evans, David R., 8

Eyles, John, 9

Falkenberg, Andreas W., 10

Fawson, Christopher, 117, 118

Findlay, A., 51, 55

Fleischmann, Arnold, 112

Flower, Patrick C., 36

Foster, Robert, 92

Frome, Michael R., 19

Fry, Prem S., 20

Fuguitt, Glenn V., 78

Galster, George, 30

Garoogian, Andrew, 37

Garoogian, Rhoda, 37

Giannias, Dimitrios A., 38, 39

Gill, Alison M., 40

Gillies, J. A., 121

Goldsmith, Marshall, 45

Gottlieb, Paul D., 93, 111

Graves, Philip E., 72, 73, 74, 75, 119

Green, Gary P., 112

Greenberg, Michael, 41

Greenwood, Michael J., 76

Gyourko, Joseph, 42, 43

Ha, Mikyoung, 64
Haigood, Traci L., 77

Halli, Shiva S., 71

Halstead, John M., 94

Harper, Wilmer M., 11

Harrison, C. M., 4

Hart, Stuart L., 95

Headey, Bruce, 12

Heaton, Tim B., 78

Henderson, Douglas A., 95

Hendon, William C., 113

Henry, Mark S., 114

Herzog, Henry W. Jr., 44

Hesselbein, Frances, 45

Heubusch, Kevin, 46, 79

Hill, John M., 7

Hoehn, John P., 29, 47

Hunter, William J., 69

Izzo, George, 115

Jacob, Jeffrey C., 80

Jeffres, Leo W., 48

Jepson, Edward J. Jr., 116

Johansen, Harley E., 127

Johnson, Julia, 25

Johnson, Kenneth M., 101

Jones, Lonnie L., 128

Joseph, A. E., 49

Kaasa, Stein, 14

Kahley, William J., 81

Kahn, James R., 33

Kanagy, Conrad L., 34

Keith, John, 117, 118

Knapp, Thomas A., 70, 119

Knowles-Lankford, Jill, 123

Kohler, Hans-Peter, 96

Kopp, Raymond J., 120

Kulshreshtha, S. N., 121

Kusmin, Lorin D., 122

Lance, Charles E., 13

Lankford, Samuel V., 123

Leven, Charles L., 61

Limb, M., 4

Linsky, Arnold S., 62

Liu, Ben-Chieh, 50, 82

Loftus, Geoffrey, 57

Lyne, Jack, 97

Mallard, Allison G.C., 13

Marcouiller, David W., 116

Mastekaasa, Arne, 14

Mathur, Vijay K., 83

McCray, Jacquelyn, 64

McFarlin, Dean B., 19

McIlravey, G. P., 49

Michalos, Alex C., 13, 84

Mills, Edwin S., 105

Mohammad, Golam, 103 
Morris, A., 51, 55

Mullis, Randolph J., 15

Murphy, Christopher A., 106

Myers, Dowell, 124

Nelson, Amy L., 58

Nord, Mark, 85

O'Brien, David J., 52

Ó hUallacháin, B., 98

Ouelette-Kuntz, Hélène, 16

Paddison, Ronan, 51

Parmenter, Trevor R., 17

Pendleton, Brian F., 18

Poloma, Margaret M., 18

Porell, Frank W., 86

Power, Thomas M., 125

Premus, Robert, 89

Ragas, Wade R., 36

Raitz, Karl, 99

Ready, Richard C., 126

Reichert, Christiane Von, 87

Rice, Robert W., 19

Roback, Jennifer, 53,54

Rogerson, R., 51, 55

Romney, David M., 20

Rosen, Sherwin, 56

Rudzitis, Gundars, 87, 127

Sauvageau, David, 57

Schlottmann, Alan M., 44

Schneider, Dona, 41

Schubert, Richard F., 45

Schwartz, Arthur L. Jr., 115

Schwirian, Kent P., 58
Schwirian, Patricia M., 58

Shermyen, Anne H., 26

Sherwood, David H., 59

Short, John R., 60

Shye, Samuel, 21

Smit, B., 49

Smith, Marc T., 26

SSID, 100

Stein, Sheldon H., 83

Stoll, John R., 128

Stover, Mark Edward, 61

Straus, Murray A., 62

Streeten, Paul, 22

Suh, Eunkook, 6

Sullivan, W. C. III, 63

Szalai, Alexander, 23

Tracy, Joseph, 43

Tweeten, Luther G., 11

Vedder, Richard K., 67

Waldman, Donald M., 75

Watson, Alan E., 102

Weber, Margaret J., 64

Weirick, William N., 65

Wheeler, Robert J., 24

White, Nancy E., 70

Williams, Al, 123

Willits, Fern K., 34

Wilson, Georjeanna, 27

Wong, Cecilia, 129

Wood, Linda A., 25

Woods, M. E., 7 